Check for updates

Cite this: Mater. Adv., 2022, 3, 1341

Received 14th November 2021, Accepted 17th December 2021

DOI: 10.1039/d1ma01070k

rsc.li/materials-advances

\section{Application of carotenoids in sustainable energy and green electronics}

\begin{abstract}
Ajay Singh (D) ${ }^{\text {ab }}$ and Trinetra Mukherjee (D) *c
In sustainable development, one of the key factors is the usage of non-toxic and biodegradable natural substances for the development of green energy and technology. Photovoltaics and photoelectrochemical cells are the most promising candidates for renewable solar energy harvesting. Currently, photovoltaics and electronic device technologies are dominated by inorganic semiconductors. Thus, there is a continuous pursuit for alternative eco-friendly semiconductors both for electronics industry and renewable energy technologies. Carotenoids are naturally found coloured pigments which are of semiconducting nature. In nature, they form an integral part of light-harvesting photosystems in photosynthetic organisms, and are also present in several non-photosynthetic organisms playing other functional roles. The structural diversity of carotenoids and their molecular nature make them ideal candidates for devices requiring photo-sensitization, and controlled electrical conduction. Here, we review the potential application of carotenoids, with their advantages, limitations and prospects for further improvement in solar cell technology, photoelectrochemical cells, semiconductor surface modification, and organic electronics in general. We emphasize on the carotenoid based renewable energy production by using carotenoid based dye-sensitized solar cells and water-splitting photoelectrochemical cells. Thereafter, we summarize some of the studies with carotenoid based nanowire, light-emitting diodes, transistors and light sensors. Though, the application of carotenoids in renewable and sustainable technologies are still in nascent stage, prospects are high for carotenoid based solar harvesting and electronic devices that are cheaper, eco-friendly, biodegradable and biocompatible.
\end{abstract}

\footnotetext{
${ }^{a}$ Department of Electrical and Computer Engineering, Technical University of Munich, Karlstraße 45, 80333 Munich, Germany. E-mail: ajay.singh@tum.de

${ }^{b}$ Department of Physics and Materials Science, University of Luxembourg, Luxembourg L-1511, Luxembourg. E-mail: ajay.singh@uni.lu

${ }^{c}$ The University of Burdwan, Burdwan, 713104 West Bengal, India. E-mail: trinetra123@gmail.com
}

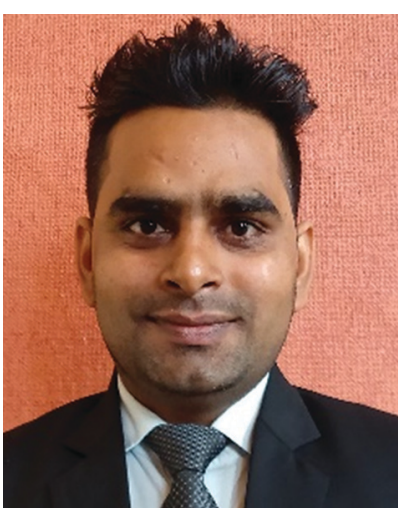

Ajay Singh
Ajay Singh is a postdoctoral researcher at the University of Luxembourg, working on developing lead-free perovskite solar cells. He obtained PhD in "Investigating charge transport in perovskite and dye-sensitized solar cells" the Technical University of Munich (TUM), Germany. He did BTech and MTech from IIT Delhi, India. His research work focuses on growing thin films for new generation photovoltaic devices. He also has expertise in drift-diffusion modeling of solar cells, LEDs, transistors, and thermoelectric nanowires. He received DAAD, CSIR-JRF/NET, and MHRD-GATE fellowships. He has worked with research groups from IIT Delhi, IISc Bangalore, IIT Roorkee, and University of Rome Tor Vergata, Italy.

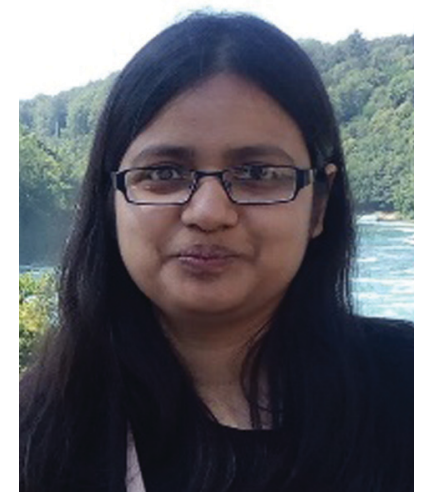

Trinetra Mukherjee
Dr Trinetra Mukherjee obtained her PhD as a DST-INSPIRE fellow in microbiology from the University of Burdwan, where she worked on the bioprospecting of extremophilic microbes from hot springs. Her research interests lie in molecular biology, bioinformatics, "omics" techniques, and the diversity analysis of various extreme habitats. She has expertise in microbial derived bioproducts with focus on chemical and functional characterization of carotenoids, enzymes, and plant growth promotion. She has worked at Ruhr University Bochum, Germany as a DAAD scholar and CSIR-IICT, India. Recently she has been awarded with MSCA-COFUND-BIENVENÜE fellowship to work at Université de Bretagne Occidentale, France. 


\section{Introduction}

Increasing demand for energy resources by human society and the depletion of conventional energy sources have made researchers think of renewable energy resources. Currently, fossil fuels share more than $80 \%$ of total energy consumption globally. Widely used fossil fuels pollute the environment and will be exhausted soon. In 2019, about 34169.0 million tonnes of carbon dioxide $\left(\mathrm{CO}_{2}\right)$ was emitted. ${ }^{1}$ The carbon footprint is significantly shared by the electronic industry, i.e., manufacturing, transport, maintenance and e-waste disposal systems. ${ }^{2-6}$ Therefore, to reduce the carbon footprint both by the energy sector and the electronic industry, it has become a need of the hour to look for renewable and green energy alternatives.

Solar fuel is one of the vastly available renewable energy source. The sunlight harvesting can be done by photoelectrochemical systems (i.e., solar water splitting) and by photovoltaic (solar cell) devices that convert the solar light into electricity. The solar cell and the electronics industry is currently dominated by inorganic semiconductor materials such as $\mathrm{Si}, \mathrm{Ga}$, GaAs, InGaAs, CIGS, GaN, CdS, $\mathrm{TiO}_{2}$, etc. Synthesis process of most of these semiconductors need controlled environment and high thermal budgets. ${ }^{7-9}$ Maintaining both the environment and the thermal budget results in increased carbon footprint. ${ }^{2,4,5}$ Also, costly wafer-synthesis process makes inorganic semiconductor devices expensive. Therefore, to develop sustainable and cost-effective technology, low-temperature processable and biodegradable materials are desired.

To investigate low-temperature, solution processable and cost-effective materials, there have been efforts to develop materials and devices based on inorganic-organic hybrid perovskite (IOHP) materials. ${ }^{10-14}$ However, their poor stability and hazardous metal content (i.e., $\mathrm{Pb}, \mathrm{Sn}$ ) have been bottlenecks in commercializing IOHP devices. ${ }^{11,15-17}$ Organic semiconductors are another class of materials that can be processed by solutions at low temperatures and are environmentally friendly. Moreover, they are light weight materials, and offer various colors, flexibility, and transparency, making them a suitable choice for printable and flexible electronics. ${ }^{18-21}$ There has been a lot of effort to develop organic semiconductor for electronic industry.

Carotenoids are naturally available organic semiconductors, and a group of natural dyes synthesized by plants, some prokaryotes and fungus ${ }^{22}$ imparting bright red, orange and yellow colours. Berries, sweet potato, carrots, banana, gardenia fruit, walnuts, ivy gourd fruit, capsicum, turmeric, pumpkin, blue pea, lemon, yellow rose, marigold flower, golden trumpet, Japanese rose, saffron, achiote seeds, annatto seeds, tangerine peel and green algae are some of the natural sources of carotenoids. Carotenoids consist of multiple C5 isoprenoid units joined together with distinct conjugated double bond system. ${ }^{23}$ These polymerized terpenoids may undergo several modifications such as cyclization at both ends, addition of methyl groups, hydrogenation, dehydrogenation, double bond migration, introduction of oxygen and other elements, esterification with fatty acids, chain shortening or extension,

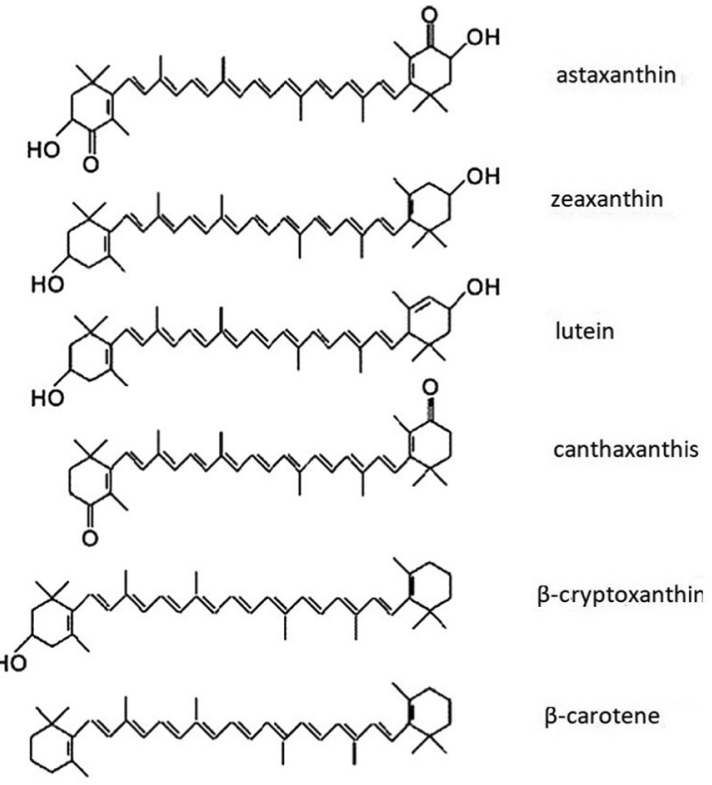

Fig. 1 Chemical structures of some of the carotenoids and all-transretinol. Figure reproduced with permission from ref. 44. Copyright (2004) Elsevier B.V.

isomerisation and rearrangement to form other carotenoids with diverse structures. ${ }^{24}$ Chemical structures for some of the carotenoids are shown in Fig. 1. More than 700 carotenoids have been discovered in nature and more carotenoids are being discovered and artificially synthesized. ${ }^{23}$ Carotenoids play a number of biological roles in living organisms. Some of these functions involve interactions with light such as photosynthesis, ${ }^{25,26}$ colouration, ${ }^{27,28}$ photoprotection ${ }^{29,30}$ and signalling. Some other functions such as improving membrane stability ${ }^{31,32}$ and antioxidant properties ${ }^{33}$ do not involve interactions with light. Some of the breakdown products of carotenoids such as retinol (Vitamin A) have been found to improve human health upon consumption. ${ }^{34}$ Several reviews have focussed on the applications of carotenoids, but they are mainly based on the current and potential use of carotenoids as functional foods, feed additive, pharmaceutical and health improvement products, ${ }^{22,35,36}$ as colourants in food and textile industry ${ }^{37-39}$ and as cosmetics and nutricosmetics. ${ }^{40-43}$ However, to the best of our knowledge, there is no review study on the potential of carotenoids in solar energy harvesting and organic electronic devices.

This review provides an overview regarding the applications of carotenoids in organic electronics and renewable energy devices. The electronic properties of carotenoids vary with the molecular structure of the carotenoids and on the number of double bonds, carbon chain length, functional groups and level of cyclization, which are highly diverse in nature. The composition of the outer environment and other binding molecules ${ }^{45}$ also influence their electronic properties. In nature, carotenoids act as light-harvesters in photosynthesis, which is the primary form of energy production. ${ }^{45,46}$ The conjugated double bond system of carotenoids plays a pivotal role in their functioning. The transition of carotenoids from ground to second 
excited state S2 leads to their strong absorption of light. Internal conversion from this excited state occurs to low level S1 state and then the ground state. These three states are responsible for most of their observed properties. The excited electrons account for the flow of electrons. ${ }^{45}$ Detailed analysis of the electronic and vibrational properties of carotenoids have been presented by several studies. ${ }^{45-49}$ Taking cues from the natural functions of carotenoids, researchers have tried to utilize these properties for man-made devices. This review starts with the potential uses of carotenoids in dye-sensitized solar cells. Carotenoids can be used as sensitizers, co-sensitizers as well as redox spacers in dye-solar cells. The next section is on the usage of carotenoids for surface modification of $\mathrm{TiO}_{2}$ (a widely used semiconductor in various electronic devices), followed by its photochemical applications for hydrogen production, a clean biofuel. Carotenoids have also found uses in organic/molecular electronics in transistors, nanowires and light-emitting diodes which forms the next section of the review. Other potential uses of carotenoids in nanotechnology and sustainable energy are also discussed. For each device, the action mechanism of carotenoids is discussed in brief followed by the state-of the-art of the most important works done, detailing on the electrical properties and efficiency of the devices containing different kinds of carotenoids. The use of carotenoids in various devices is a way forward towards green technology as carotenoids are non-toxic even at high doses. ${ }^{50,51}$ However one of the major problems with carotenoids which limits their use, is their instability, once they are purified from their natural sources. ${ }^{52}$ Researchers have tried to improve the stability and efficiency of carotenoid containing devices and many of them have been successful to some extent. However, the potential of carotenoids in this respect have not been fully realised till date. This review brings together the significant findings of this field, analyses the outcomes and persisting problems to find solutions for advancement of this technology.

\section{Dye-sensitized solar cells}

In carotenoids, eight isoprene units form a C40 backbone, which allow them to absorb solar spectrum in the wavelength range from $380-550 \mathrm{~nm} .{ }^{53}$ Upon light absorption, electrons from HOMO (highest occupied molecular level) are excited to LUMO (lowest unoccupied molecular level) of the carotenoid. The excited electrons can be collected into an external circuit, resulting in a current flow. This photosensitizing property of carotenoids makes them a potential candidate for sensitizers in dye-sensitized solar cells (DSCs).

In a DSC, a mesoporous scaffold (usually $\mathrm{TiO}_{2}$ ) is grown on a glass/FTO or glass/ITO, followed by a dye monolayer. A redox mediator (or a hole conductor) is filled on top of the dye monolayer, followed by an electrode, a transparent conductor and glass layer. Upon illumination, the dye absorbs the sunlight and electrons from the dye HOMO are transferred to the dye LUMO. The LUMO electrons are injected into the $\mathrm{TiO}_{2}$, and the dye is regenerated by the redox mediator. The charge transfer from the dye into the $\mathrm{TiO}_{2}$ is mediated by a radical

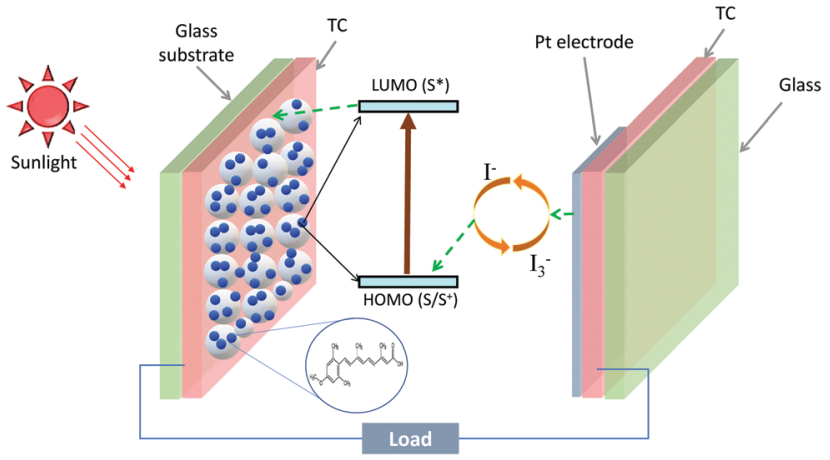

Fig. 2 Working principle of a dye-sensitized solar cell (DSC). Big white sphere represent porous $\mathrm{TiO}_{2}$, and the small blue spheres represent dye molecules. Upon light absorption electrons from the dye HOMO go to the dye LUMO, and are ultimately transferred to transparent conductor (TC: FTO/ITO) via $\mathrm{TiO}_{2}$. The dye is regenerated by a redox mediator, typically $\mathrm{I}^{-} / \mathrm{I}_{3}^{-}$. Inset circle shows an exemplar organic dye used in a DSC.

cation $\left(\mathrm{S}^{\bullet+}\right)$ of the sensitizer $(\mathrm{S})$, and can be explained by the following equation: ${ }^{54,55}$

$$
\mathrm{S} \stackrel{h \nu}{\longrightarrow} \mathrm{S}^{*} \stackrel{\mathrm{TiO}_{2}}{\longrightarrow} \mathrm{S}^{\bullet+} \rightarrow \mathrm{TiO}_{2}\left(\mathrm{e}^{-}\right)
$$

The complete charge transfer cycle is explained in Fig. 2. Conventional DSCs use $\mathrm{I}^{-} / \mathrm{I}_{3}{ }^{-}$as a redox mediator. Many other redox mediators and hole transporting materials have also been demonstrated. ${ }^{56}$ Typically used dyes are made up of metal complexes or organic absorbers. Metal-based dyes have a narrow absorption window, are expensive, and available in a limited number. On the other hand, organic dyes have much higher absorption coefficients and are available in abundance. Carotenoids are naturally available, easy to synthesize, and environmental friendly organic dyes. Their absorptive capability, and molar extinction coefficients $\sim 1 \times 5$, make them a suitable choice for a photosensitizer layer attached to a porous $\mathrm{TiO}_{2}$ surface. Moreover, due to the presence of natural extracts, carotenoids can prevent electrolyte recombination, improve dye adsorption, and decrease dye accumulation. ${ }^{57-60}$

In 2000 , Gao et al. ${ }^{49}$ demonstrated that $8^{\prime}$-apo- $\beta$-caroten- $8^{\prime}$ oic acid (carotenoid) deposited on a mesoporous $\mathrm{TiO}_{2}$ can lead to a photocurrent upon illumination. By using a mixture of aqueous $10 \mathrm{mM} \mathrm{H} 2 \mathrm{Q}$ (hydroquinone) and $0.1 \mathrm{M} \mathrm{NaH} \mathrm{PO}_{4}$ solution as a redox mediator, they could obtain incident monochromatic photon-to-photocurrent conversion efficiency (IPCE) of about $34 \%$. They illuminated a cell area of 0.25 by using 40 monochromatic light at $426 \mathrm{~nm}$ and obtain a short-circuit current $\left(J_{\mathrm{sc}}\right)$ of 4.6 . Thereafter, several attempts have been made to utilize carotenoids as photosensitizer in dyesensitizer solar cells (DSCs). Some of the carotenoid-based sensitizers (for DSCs) are summarized in Table 1. For some of the studies mentioned in the table, exact carotenoid compositions were not determined. And therefore, a mixture of carotenoids can be present. In the table, (a) represents zeaxanthin dipalmitate (major) and other carotenoids. ${ }^{61}$ (b) Represents violaxanthin, antheraxanthin, zeaxanthin, capsanthin, capsorubin and capsanthin-5,6-epoxide, lutein, and $\beta$-cryptoxanthin to be the 
Table 1 Carotenoid based solar cells

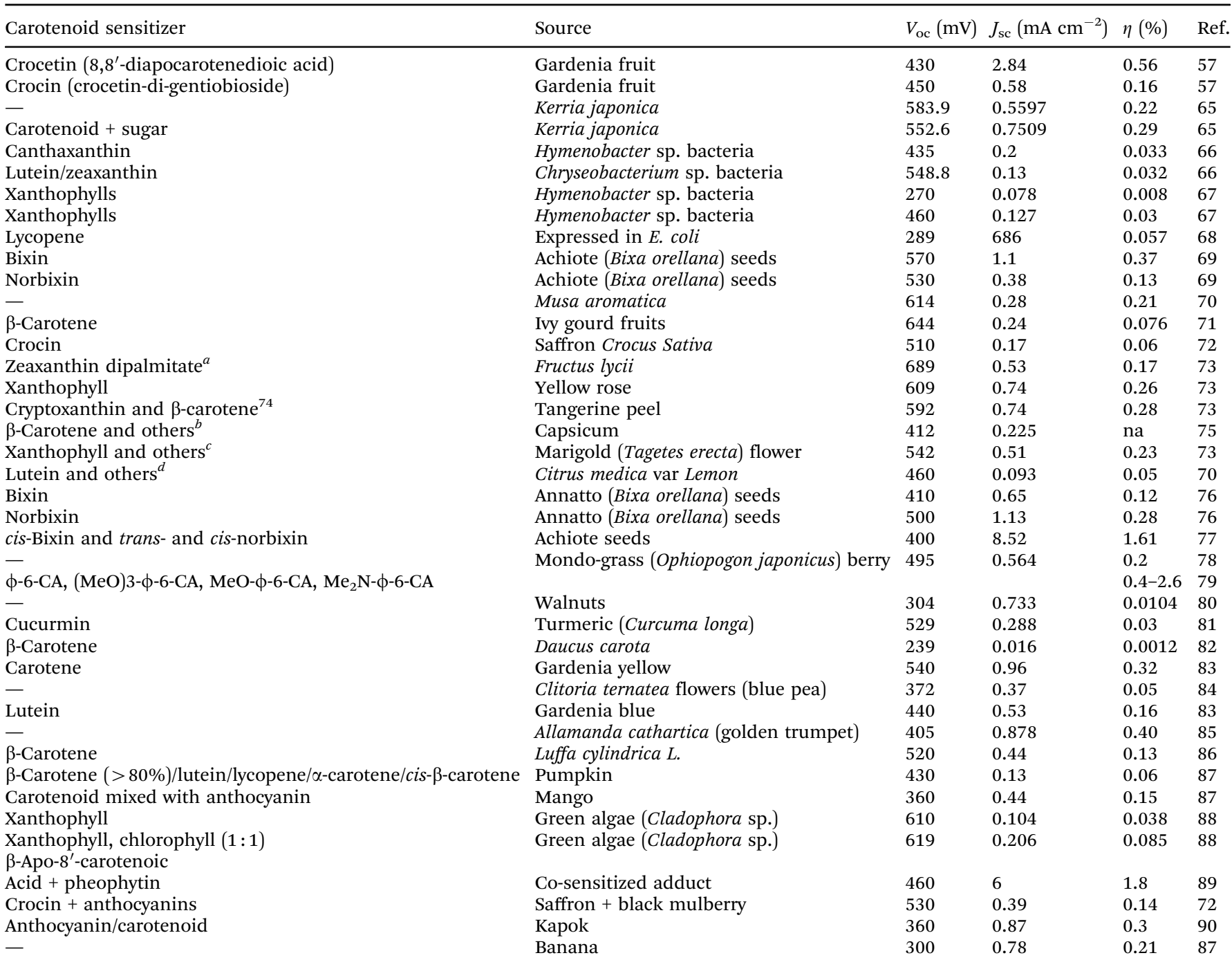

For $a-d$, exact carotenoid compositions were not determined, and hence compositions of multiple carotenoids can be present. See text for more information

possible carotenoids. ${ }^{62}$ (c) Represents lutein esters (88\%), all-cis and trans isomers of lutein, and all-cis and trans isomers of zeaxanthin $(5 \%){ }^{63}$ (d) Represents zeaxanthin $\beta$-cryptoxanthin, and $\beta$-carotene to be the possible carotenoids. ${ }^{64}$

Yamazaki et al. ${ }^{57}$ used crocetin (8,8'-diapocarotenedioic acid) and crocin (crocetin-di-gentiobioside) as photosensitizers in DSCs. They observed that due to the presence of carboxylic groups in the molecule, crocetin shows increased binding affinity to the porous $\mathrm{TiO}_{2}$ surface. Increased $\mathrm{TiO}_{2}$-dye binding results in increased pore-filling and efficient electron injection from crocetin molecules to $\mathrm{TiO}_{2} \cdot{ }^{91,92}$ Short-circuit photocurrents of $2.84 \mathrm{~mA}$ and $0.45 \mathrm{~mA}$ were reported for the cells based on crocetin and crocin, respectively. Hemalatha et al. employed carotenoid extracted from Kerria japonica in dye-sensitizer. ${ }^{65}$ Further they treated the carotenoid by sugar molecules. They obtained solar cell efficiencies of $0.29 \%$ and $0.22 \%$ with and without sugar molecules, respectively. They found that the addition of sugar molecules results in an increased $J_{\text {sc }}$ (from $0.5597 \mathrm{~mA} \mathrm{~cm}^{-2}$ to $0.7509 \mathrm{~mA} \mathrm{~cm}^{-2}$ ) and a reduced $V_{\mathrm{oc}}$ (from $583.9 \mathrm{mV}$ to $552.6 \mathrm{mV}$ ).

Shanmugam et al. used $\beta$-carotene extracted from ivy gourd fruits as sensitizers for DSCs. ${ }^{71}$ They obtained poor DSC efficiency $(0.076 \%)$, which could be due to poor binding of $\beta$-carotene to the $\mathrm{TiO}_{2}$ surface as $\beta$-carotene does not have carboxylic or hydroxyl groups. Poor pore filling and poor binding of dye molecules to the $\mathrm{TiO}_{2}$ surface results in poor electron injection from the $\beta$-carotene dye to $\mathrm{TiO}_{2}{ }^{71,91,92}$ In another study, Eka et $a l^{70}$ extracted carotenoids from Citrus medica var. Lemon and Musa aromatica and used them as photosensitizers for DSCs with $\mathrm{TiO}_{2}$ Nanoparticle. They obtained power conversion efficiencies of $0.21 \%\left(J_{\mathrm{sc}}=0.28\right.$, $\left.V_{\mathrm{oc}}=0.614 \mathrm{~V}\right)$ and $0.05 \%\left(J_{\mathrm{sc}}=0.093, V_{\mathrm{oc}}=0.460 \mathrm{~V}\right)$ for the cells based on Musa aromatica and Citrus medica var. Lemon sensitizers, respectively. Here, $V_{\text {oc }}$ represents open-circuit voltage.

Wang et al. ${ }^{93}$ used $\beta$-carotene, lycopene and fucoxanthin carotenoids as electron-donor molecules in organic solar cells. 
They used a fullerene derivative[6,6]-phenyl-C61-butyric acid methyl ester (PCBM) as electron-acceptor. They obtained improvement in the photovoltage and the efficiency upon inclusion of carotenoids. The $J_{\mathrm{sc}}$ improvement was ranked as lycopene $>\beta$-carotene $>$ fucoxanthin. While, the increase in the $V_{\text {oc }}$ was ranked as, lycopene $<\beta$-carotene $<$ fucoxanthin. Caloger et al..$^{77}$ extracted apocarotenoids from the achiote seeds and used them to fabricate stable DSCs and DSC modules. They observed incident photon-to-electron conversion efficiency (IPCE) as high as $33 \%$, resulting in efficiency $\eta \sim 1.6 \%$. Most importantly, they obtained dye-sensitized solar cell modules exceeding $1000 \mathrm{~h}$ of stable performance under 1 sun, producing a battery capacity of $\sim 46.8 \mathrm{~A} \mathrm{~h}$. These results are encouraging towards large scale fabrication of cost-effective, non-toxic, stable and environmentally friendly DSCs.

Many studies have demonstrated the use of carotenoids as a sensitizer for DSCs. However, there are more than 700 known carotenoids, but very few of them have been investigated for photovoltaic applications. The main reason behind this is that, most of the carotenoids (studied so far) are not adhesive to the $\mathrm{TiO}_{2}$ surface due to lack of effective functional groups. In addition, long alkyl chains of the carotenoids present with a strong steric hindrance prevent the dye molecules from arraying efficiently onto the mesoporous scaffold of $\mathrm{TiO}_{2} \cdot{ }^{53}$ Further studies are needed to investigate carotenoids consisting of functional groups that interact with $\mathrm{TiO}_{2}$ and other scaffold such as $\mathrm{SnO}_{2}$, $\mathrm{ZnO}$, NiO, etc. Moreover, studies are needed to develop artificial carotenoid derivatives with suitable functional groups and excellent optoelectronic properties.

\subsection{Carotenoids as co-sensitizers}

Since the carotenoids have photosensitizing as well as redox nature, they can be used as co-sensitizers where they serve two fold purpose. Wang et al. reported use of pheophytincarotenoid adduct and pheophytin derivative sensitizers. ${ }^{89}$ Upon addition of carotenoid moiety, the cell $J_{\mathrm{sc}}$ and $\eta$ increase from 3.7 and $1.4 \%$ to 6 and $1.8 \%$, respectively. In another study, addition of saffron carotenoids to mulberry anthocyanins (photosensitizer) was reported to broaden the absorbance band. $^{72}$ This results in increased $V_{\text {oc }}$ of the cell $(0.44 \mathrm{~V}, 0.51 \mathrm{~V}$, and $0.53 \mathrm{~V}$ for saffron carotenoids, mulberry anthocyanins, and $50: 50$ mixture of both, respectively).

Lim et al. used a mixture (1:1) of chlorophyll and xanthophyll as sensitizer. ${ }^{88}$ Upon addition of xanthophyll in chlorophyll, all the photovoltaic parameters were increased. In comparison to pure chlorophyll $\left(V_{\mathrm{sc}}=585 \mathrm{mV}, J_{\mathrm{sc}}=0.145, \mathrm{FF}=0.59, \eta=0.055 \%\right)$ and pure xanthophyll $\left(V_{\mathrm{sc}}=610 \mathrm{mV}, J_{\mathrm{sc}}=0.104, \mathrm{FF}=0.54\right.$, $\eta=0.038 \%)$, the mixture resulted in increased $V_{\mathrm{oc}}(585 \mathrm{mV}), J_{\mathrm{sc}}$ (0.206), FF (0.60), and $\eta(0.085 \%)$ were obtained. Zhuang et al. ${ }^{94}$ employed lycopene carotenoid aggregates as electron donors and chlorophyll derivatives as electron acceptors to demonstrate natural-photosynthesis-inspired photovoltaic cells. In another study, Petrella et al..$^{95}$ presented a photoelectrochemical study on bulk and nanocrystalline $\mathrm{ZnO}$ films sensitized by carotenoids, chlorophyll $a$ and their mixture. They found the photoconversion process to be greatly enhanced upon sensitization with a dye mixture, as compared to individual chlorophyll $a$ and carotenoids. Along with improved power conversion efficiencies, the carotenoids prevent oxidation damage of the chlorophyll, leading to more stable DSCs while employing the mixture.

\subsection{Carotenoids as redox spacer}

Because of excellent electron transport properties of carotenoids, they can also be used as redox spacers in DSCs. Wang et al. used neurosporene $(n=9)$, spheroidene $(n=10)$, lycopene $(n=11)$, anhydrorhodovibrin $(n=12)$ and spirilloxanthin $(n=13)$ carotenoids as redox spacers in dye-sensitized solar cells. ${ }^{96}$ Here, $n$ represents the numbers of conjugated double bonds in the given carotenoid. The conjugated redox spacer blocks reverse electron transfer from $\mathrm{TiO}_{2}$ to dye, and neutralize the dye radical cation. Using a chlorophyll $a$ derivative as photosensitizer in conjuction with carotenoid redox spacer, they reported up to $\simeq 30 \%$ enhancement in the efficiency in the presence of carotenoid redox spacers. The current density increased from 10.1 (no carotenoid) to 11.5 (with spirilloxanthin, $n=13$ ). This results in increased efficiency from $3.1 \%$ (with no carotenoid) to $4.0 \%$.

Wang et al. ${ }^{97}$ employed $20 \%$ of neoxanthin, violaxanthin, lutein and $\beta$-carotene as Car redox spacers in DSCs with PPB $a$ sensitizer. These carotenoids consist of 8-10 conjugated double bonds. They proposed a electron transfer mechanism from Car to PPB $a$ leading to enhancement of photocurrent while decreasing the electron-oxidation potential of Car. The photovoltaic performance parameters are summarized in Table 2 .

\subsection{Further improvements}

There have been efforts to overcome the limitations presented by the carotenoid sensitizers. Yamanzaki et al. ${ }^{57}$ presented a comparative study on crocetin and crocin carotenoids sensitizers on $\mathrm{TiO}_{2}$. They observed that, due to the carboxylic groups present in crocetin, it shows high binding ability to the $\mathrm{TiO}_{2}$ surface. An improved pore filling and better contact with $\mathrm{TiO}_{2}$ maps into increased charge injection from the crocetin into $\mathrm{TiO}_{2}$, as compared to crocin.

Wang et al. ${ }^{96}$ investigated carotenoid conjugated spacers with number of conjugated double bonds, $n=9-13$. They found spirilloxanthin carotenoid, $(n=13)$ to be the best spacer. More spacers should be investigated corresponding to different sensitizers and mesoporous scaffolds. In another study, Wang et al. ${ }^{98}$ fabricated DSCs with carotenoic acids (CA) and retinoic acid (RA) having 5-13 conjugated double bonds, $n$. They observed

Table 2 Photovoltaic performance parameters of DSSCs employing PPB $a$ as the sensitizer and carotenoids (Cars) as redox spacers (by 20\%). Reprinted from ref. 97 with permission from Elsevier, Copyright (2006) Elsevier B.V.

\begin{tabular}{llllll}
\hline$n$ & PPB a/Car & $J_{\text {sc }}\left(\mathrm{mA} \mathrm{cm}^{-2}\right)$ & $V_{\text {oc }}(\mathrm{mV})$ & FF & $\eta(\%)$ \\
\hline & No Car & $10.6(0)$ & 0.54 & 0.60 & 3.4 \\
8 & +Neoxanthin & $11.8(+1.2)$ & 0.55 & 0.60 & 3.9 \\
9 & +Violaxanthin & $11.4(+0.8)$ & 0.54 & 0.61 & 3.7 \\
10 & +Lutein & $12.5(+1.9)$ & 0.54 & 0.59 & 4.0 \\
11 & + $\beta$-Carotene & $13.7(+3.1)$ & 0.53 & 0.58 & 4.2
\end{tabular}




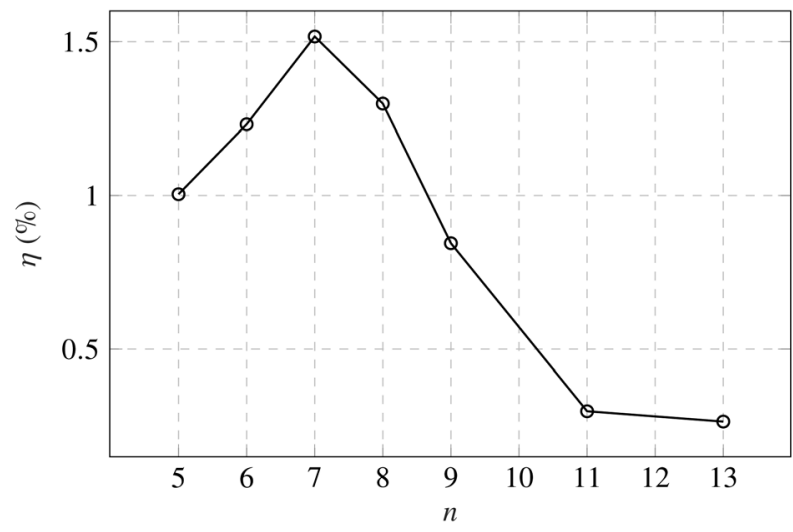

(a)

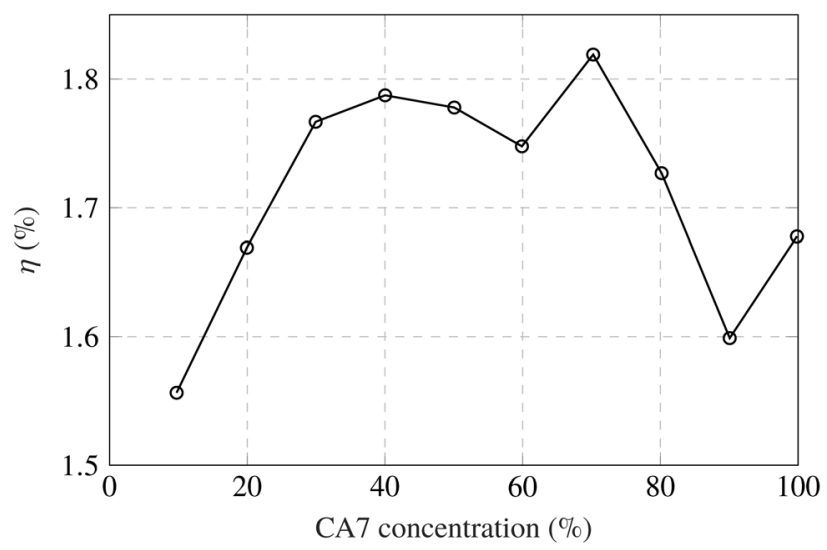

(b)

Fig. 3 (a) DSC efficiency $(\eta)$ dependence on number of conjugated double bonds $(n)$ in carotenoic acids and retinoic acid. (b) Efficiency dependence on CA7 concentration in deoxycholic acid. Figures are adopted with permission from ref. 98. Copyright 2005 Elsevier B.V.

maximum photocurrent and the PEC for $n=7$. The order for incident photon-to-electron efficiency (IPCE) was observed such that IPCE profile at $420 \mathrm{~nm}$ is maximum for CA7. The IPCE decreases in the following order: CA7 $>$ CA8 $>$ CA6 $>$ RA5 $>$ CA9 $>$ CA11 > CA13, where CA7 is carotenoic acid with 7 conjugated double bonds, and so on. However, the order for the photocurrent density was found to be: CA7 $>$ CA8 $>$ CA6 $>$ CA9 $>$ RA5 $>$ CA11 $>$ CA13. This infers that the charge injection efficiencies are not in the same order as the IPCE. Furthermore, they studied the role of CA7 dilution with deoxycholic acid. They found the optimum concentration of CA7 to be about $70 \%$. Measured efficiencies are shown in Fig. 3.

Adding sugar molecules and other functional groups could also be helpful in improving the DSCs performance as reported by Hemalatha et al. ${ }^{65}$ Another way to develop efficient carotenoid-sensitized solar cells is to develop carotenoid analogs with better photophysical properties and bonding with mesoporous scaffold. $^{79}$

One important issue with the DSCs is poor long-term stability. ${ }^{99,100}$ Several metal-complex dyes undergo degradation in presence of a liquid electrolyte. There are carotenoids obtained from thermophilic and extremophilic microorganisms. ${ }^{33,101}$ Exploring thermophilic carotenoids for electrochemical and photovoltaic applications could be a way to develop highlystable DSCs.

\section{$3 \mathrm{TiO}_{2}$ surface modification}

Because of semiconducting, transparency, excellent photocatalytic properties, and chemically and biologically inert nature, titanium dioxide $\mathrm{TiO}_{2}$ is one of the most widely used semiconductors in electronic, optoelectronic and electrochemical devices, for oxidation of hazardous chemicals, reduction of heavy metal ions, photodestruction of bacteria and viruses in water, and several other environmental applications. ${ }^{102-108}$

In semiconductor devices, electron-hole $\left(\mathrm{e}-\mathrm{h}^{+}\right)$recombination time is a very important parameter in determining charge injection and charge transport. Higher recombination time results in less recombination and hence a better charge transport/injection. $\mathrm{TiO}_{2}$ exhibit very fast $\mathrm{e}-\mathrm{h}^{+}$recombination (i.e., <10 ns). Moreover, exponential trap tails near the surface of $\mathrm{TiO}_{2}$ can lead to recombination of the charges injected by other layers. ${ }^{91,106,107}$ In this case, bulk and surface modification of $\mathrm{TiO}_{2}$ can help to improve charge injection, charge collection, and charge transport in general. ${ }^{109,110}$ Adsorption of functional molecules that coordinate efficiently to the $\mathrm{TiO}_{2}$ surface can allow efficient charge separation, and hence improve the photocatalytic properties of $\mathrm{TiO}_{2} \cdot{ }^{107,110}$ Carotenoids contain special functional groups that can be adsorbed by $\mathrm{TiO}_{2}$, and can block surface trapping sites of photogenerated/injected charge carriers.

Studies have suggested that $\mathrm{OH}$ groups can be replaced by carboxylate groups at the $\mathrm{TiO}_{2}$ surface, followed by chemical binding of carboxylate groups with $\mathrm{Ti}$ atoms. Several carotenoids contain terminal $-\mathrm{CO}_{2} \mathrm{H}$ groups that can strongly bind with the $\mathrm{TiO}_{2}$ surface. ${ }^{111-113}$ Wang et al. ${ }^{96}$ demonstrated that CA7 (carotenoic acid with 7 conjugated double bonds) has carboxylic groups, which can strongly binds to the $\mathrm{TiO}_{2}$ surface. The strong binding results in nearly $100 \%$ charge injection from CA7 to $\mathrm{TiO}_{2}$. They also observed that CA7 intrinsically generates triplet when electrons accumulate on $\mathrm{TiO}_{2}$ surface.

Because of wide bandgap $\left(E_{\mathrm{g}} \simeq 3.2 \mathrm{eV}\right)$ nature of $\mathrm{TiO}_{2}$, it shows optical transparency in the visible light region. Therefore, $\mathrm{TiO}_{2}$ is used as charge transport layer rather than an absorber in solar cells and photoelectrochemical cells. To use photoactivity of $\mathrm{TiO}_{2}$ in the visible part of solar spectrum, photosensitization using adsorption of dye molecules is desired which have high extinction coefficients in the visible light. Konovalova et al. ${ }^{107}$ studied charge separation at the surface of carotenoid-modified $\mathrm{TiO}_{2}$ nanoparticles of $7 \mathrm{~nm}$ in size. They employed carotenoid molecules containing terminal carboxy groups $\left(-\mathrm{CO}_{2} \mathrm{H}\right)$. It was observed that, strong complexation of $\left(-\mathrm{CO}_{2} \mathrm{H}\right)$ groups with the nanoparticle surface results in electron transfer from the carotenoid molecule to the surface trapping sites of $\mathrm{TiO}_{2} \cdot{ }^{107} \mathrm{Upon}$ surface modification by $8^{\prime}$-apo- $\beta$-caroten- 8 -aldoxime carotenoid, $\mathrm{TiO}_{2}$ absorption spectra changes significantly, as shown in Fig. 4a. 


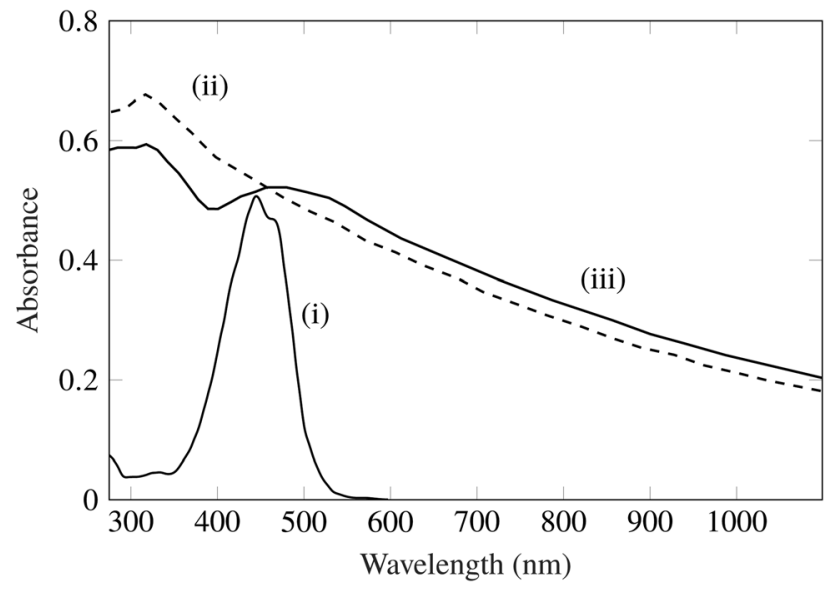

(a)

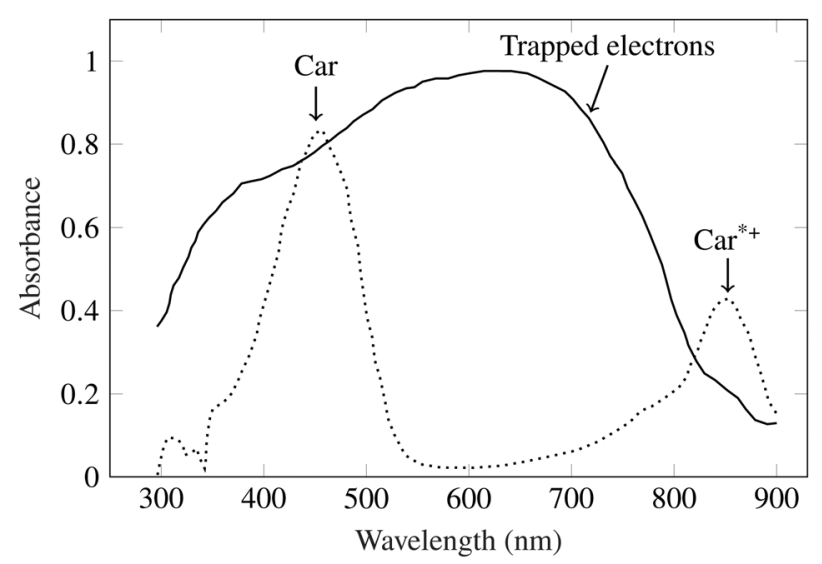

(b)

Fig. 4 (a) Absorption spectra of (i) $8^{\prime}$-apo- $\beta$-caroten- $8^{\prime}$-aldoxime, (ii) bare $\mathrm{TiO}_{2}$ nanoparticles (dashed line) and (iii) $8^{\prime}$-apo- $\beta$-caroten- $8^{\prime}$ aldoxime modified $\mathrm{TiO}_{2}$. All the spectra were recorded in acetonitrile solution. (b) Absorption spectra of $7^{\prime}$-apo-7'-(4-carboxyphenyl)- $\beta$ carotene modified $\mathrm{TiO}_{2}$ nanoparticles in $\mathrm{CH}_{2} \mathrm{Cl}_{2}$ (solid line), and solution of $7^{\prime}$-apo-7'-(4-carboxyphenyl)- $\beta$-carotene in $\mathrm{CH}_{2} \mathrm{Cl}_{2}$ treated with $\mathrm{FeCl}_{3}$ ( $<1$ equiv.) (dotted line). Figures are adopted with permission from ref. 107. Copyright 1999 American Chemical Society.

Similarly, a change in $\mathrm{TiO}_{2}$ absorption spectra was observed while employing 7 -apo-7'-(4-carboxyphenyl)- $\beta$-carotene as surface modifier, as shown in Fig. $4 \mathrm{~b}$.

In another study by Pan et al., trans-8'-apo- $\beta$-caroten- $8^{\prime}$-oic acid (1) was used to attach pheophytin $a$ (2) to help sensitize nanocrystalline $\mathrm{TiO}_{2}$ film immersed in a hydrated ethanol solution. ${ }^{114}$ Hydrophilic $\mathrm{TiO}_{2}$ surface exhibits weak interaction with the molecule 2 . Self-assembled monolayer of 1 helps 2 to form a self-assembled carotenoid-pheophytin (Car-Ph) system attached to the $\mathrm{TiO}_{2}$. The resultant Car-Ph system leads to a reductive quenching of the pheophytin moiety. Also, formation of a long-lived charge-separated state is observed suggesting that the "self-assembling" strategy could be adopted for novel DSCs.

Alwis et al. $^{76}$ studied photostability of two apocarotenoids, norbixin and bixin on the surface of semiconductor $\mathrm{TiO}_{2}$ nanoparticles. Both the carotenoids exhibit similar photodegradation kinetics upon light exposure. $\mathrm{TiO}_{2}$ might act as a catalyst for photodegradation process by forming a photochemically induced radical cation of the carotenoids. The photodegradation rate increases in the presence of $\mathrm{O}_{2}$. Norbixin based DSCs show the photocurrent conversion efficiency twice than that of bixin based cells. Further research is needed to study the degradation process and the ways to mitigate the degradation. Carotenoid-based surface modification technique can also be helpful for improving photocatalytic activity, shifting absorption spectrum and modifying energy levels of $\mathrm{TiO}_{2}$ charge transport layers in photovoltaics, light-emittingdiodes and photochemical devices.

\section{Solar water splitting and other photoelectrochemical applications}

A (water-splitting) photoelectrolytic cell (PEC) is a type of photoelectrochemical cell that electrolizes water into oxygen and hydrogen gas by irradiating the anode with light. PCE has been regarded as a potential way of harvesting solar energy by hydrogen fuel generation. ${ }^{115-118}$ Ever since $\mathrm{TiO}_{2}$ was reported to exhibit the water splitting ability in PEC, there have been intensive efforts to develop photoelectrode materials for solar hydrogen production. ${ }^{118,119}$ As mentioned in the previous section, $\mathrm{TiO}_{2}$ is a wide bandgap semiconductor and therefore uses only a small part of the solar spectrum. Sensitizing $\mathrm{TiO}_{2}$ surface with a photosensitizing dye molecule broadens the absorption spectrum and therefore can utilize the solar spectrum in a better manner. ${ }^{107,110,116}$

A conventional PEC consists of a working photoelectrode (such as $\mathrm{TiO}_{2}$ ) and a counter electrode (i.e., Pt cathode) immersed in an electrolyte. Upon sunlight absorption, photoelectrons are generated in $\mathrm{TiO}_{2}$ (or dye-sensitized $\mathrm{TiO}_{2}$ ). Fig. 5 shows a typical water splitting process in a photoelectrochemical cell. The electrons from the $\mathrm{TiO}_{2}$ conduction band (CB) migrate via external circuit to the counter electrode. The electrons at the counter electrode reduce water molecules into hydrogen. The photogenerated holes in the $\mathrm{TiO}_{2}$ valence band (VB) oxidize water molecules to oxygen. Ideally, the VB energy level should be higher than the $\mathrm{O}_{2} / \mathrm{H}_{2} \mathrm{O}$ redox potential, and $\mathrm{CB}$ energy level should be lower than the $\mathrm{H}^{+} / \mathrm{H}_{2}$ redox potential. To increase the water-splitting yield, Pt electrode can be replaced with a semiconductor photoelectrode, and this architecture is known as bi-photoelectrode PEC.

Carotenoids have shown excellent photochemical properties attracting their applications in PECs. ${ }^{95,107,120}$ Polyyakov et al. ${ }^{121}$ employed $\beta$-carotene to improve photocatalytic activity of $\mathrm{TiO}_{2}$ nanoparticles in the visible light. They employed electron paramagnetic resonance (EPR) spin-trapping technique to study the photocatalytic response. It was observed that a water-soluble natural polysaccharide arabinogalactan complex of $\beta$-carotene significantly enhances the yield of the reactive hydroxyl $(\mathrm{OH})$ radicals. The enhancement could be due to the decrease in the back electron transfer from the $\mathrm{TiO}_{2}$ nanoparticles to the carotenoid radical cation. The study explains the charge transfer mechanism and the importance of controlling the back 


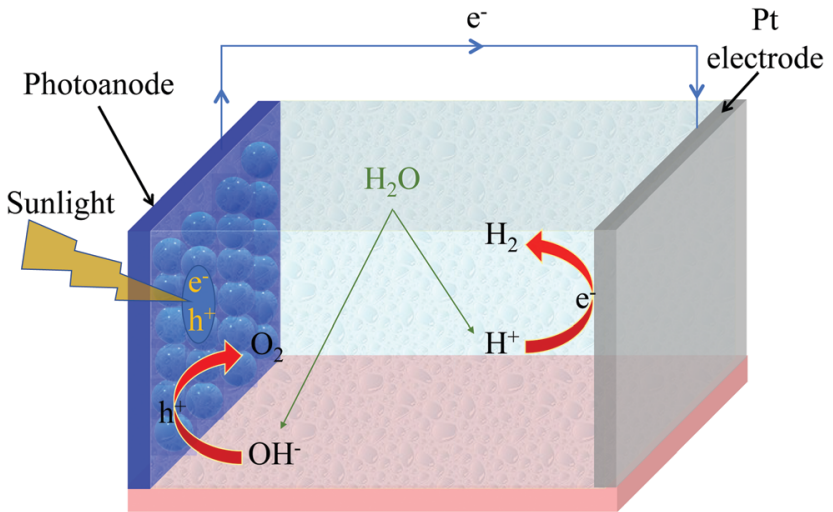

Fig. 5 Water splitting scheme in a photoelectrochemical cell. Sunlight incident on a semiconductor photoanode leads to electron-hole pair generation. The photogenerated electrons travel to the Pt electrode (cathode) via an external circuit. The electrons at the cathode reduce $\mathrm{H}^{+}$ ions into $\mathrm{H}_{2}$. The photogenerated holes at the cathode oxidize $\mathrm{OH}^{-}$ions to produce $\mathrm{O}_{2}$.

electron transfer. These results are helpful to develop carotenoid based PCEs with increased efficiency.

Carotenoid based dyad and triads have been used to develop reaction centers and sensitizers to develop sensitizers and reaction centers (RCs) to mimic the photosynthesis process. ${ }^{122-126}$ Some of the carotenoid-based light harvesting complexes and RCs are summarized in Table 3. A comprehensive review on light-harvesting systems utilizing carotenoids have been presented by Hashimoto et al. ${ }^{127}$ Kodis et al. ${ }^{128}$ presented a carotene-porphyrin-fullerene (triad) model for artificial photosynthetic RCs with potential applications in photochemical and photoelectrochemical devices. They reported that the triad (as shown in Fig. 6b) undergoes a photoinduced electron transfer (PET). The PET process is followed by a charge shift to generate a $\mathrm{C}^{\bullet+}-\mathrm{P}^{-}-\mathrm{C}_{60}{ }^{\bullet-}$ charge-separated state. The overall yield of the charge transfer and the charge shift approaches unity. Furthermore they found that the state shows a decay time constant of $57 \mathrm{~ns}$ and produces about $1 \mathrm{eV}$ of electrochemical potential.
The stored energy can be used for solar water splitting and other solar fuel generation. ${ }^{48,129-131}$

Wilson et al. demonstrated thylakoids based photosystem II (PSII) extracted from spinach leaves for photosynthetic water splitting. ${ }^{132}$ Their absorbance and surface-enhanced Raman spectra (SERS) suggested the PSII to be consisting of $\beta$-carotene and chlorophyll. They further studied the structural dynamics of the oxygen evolving complex (OEC) of photosystem II during the water splitting reaction. By analyzing SERS spectra in conjunction with density-functional theory (DFT) calculations, they predicted $\mathrm{S}_{0}-\mathrm{S}_{3}$ intermediates states within catalytic cycle of the OEC. Wang et al. ${ }^{130}$ developed a hybrid solar water splitting system by combining natural and artificial photocatalysts. They used the natural PSII from spinach (consisting of $\beta$-carotene and chlorophyll) along with inorganic photocatalysts (i.e., $\mathrm{Ru} / \mathrm{SrTiO}_{3}: \mathrm{Rh}$ ). The inorganic photocatalysts were coupled with an inorganic electron shuttle $\left[\mathrm{Fe}(\mathrm{CN})_{6}{ }^{3-} / \mathrm{Fe}(\mathrm{CN})_{6}{ }^{4-}\right]$. The whole integrated photocatalyst system was dispersed in aqueous solutions. They obtained the hybrid photosystem activity to be about $2489 \mathrm{~mol} \mathrm{H}_{2}$ (mol PSII) ${ }^{-1} \mathrm{~h}^{-1}$ under visible light irradiation. Upon inclusion of PSII from spinach, the solar water splitting yield increases up to four times as compared to the system based on only-inorganic photocatalysts. Moreover, polyenes present in $\beta$-carotene lead to quenching of chlorophyll triplet states providing photoprotection by oxygen damage. ${ }^{48}$ The charge quenching in chlorophyllzeaxanthin carotenoid systems is represented in Fig. 7 as explained by Park et al. ${ }^{133}$

The carotenoid takes part in nonphotochemical quenching (NPQ) regulatory mechanism. The quenching process consists of excitation energy transfer (EET) quenching and charge transfer (CT). EET takes place when the Chl-Qy state transfers energy to the Car $\mathrm{S}_{1}$ state. Since the Car chS1 state has very short lifetime $(\sim 10 \mathrm{ps})$ compared to Chl-Qy state lifetime $\left(>1 \mathrm{~ns}\right.$ ), the $\mathrm{S}_{1}$ state undergoes a rapid de-excitation. In some cases, a bidirectional Chl-Qy Car $\leftrightarrow \mathrm{S}_{1}$ energy transfer can take place. The CT quenching is mediated by a transient state composed of $\mathrm{Chl}^{\bullet-}$ and $\mathrm{Car}^{\bullet+}$. From the transient state, the charges then undergo a fast recombination process $(\geq 40 \mathrm{ps})$.

Table 3 Some of the carotenoid-based reaction centers (RCs) and light-harvesting complexes. The table is adapted from ref. 127 with permission from Elsevier, Copyright (2015) Elsevier Ireland Ltd

Antenna systems from prokaryotes

\begin{tabular}{|c|c|c|c|}
\hline Name & Type of RC & Oxygenic/anoxygenic & Carotenoids \\
\hline Heliobacteria & Type I (FeS) & Anoxygenic & Diaponeurosporene \\
\hline Green sulfur bacteria & Type I (FeS) & Anoxygenic & Isorenieratene \\
\hline Purple bacteria & Type II (quinone) & Anoxygenic & Spheroidene, spirilloxanthin \\
\hline Filamentous green bacteria & Type II (quinone) & Anoxygenic & $\gamma$-Carotene, $\beta$-carotene \\
\hline Cyanobacteria & PS I (FeS)/PS II (quinone) & Oxygenic & $\beta$-Carotene, zeaxanthin \\
\hline
\end{tabular}

Antenna systems from eukaryotes

Name

Chlorophytes, green algae

Red algae

Dinoflagellates

Cryptophytes

Heterokontophyta, haptophyta
Carotenoids

$\beta$-Carotene, lutein, neoxanthin, violaxanthin Zeaxanthin Peridinin $\alpha$-carotene, alloxanthin Fucoxanthin 
(a)

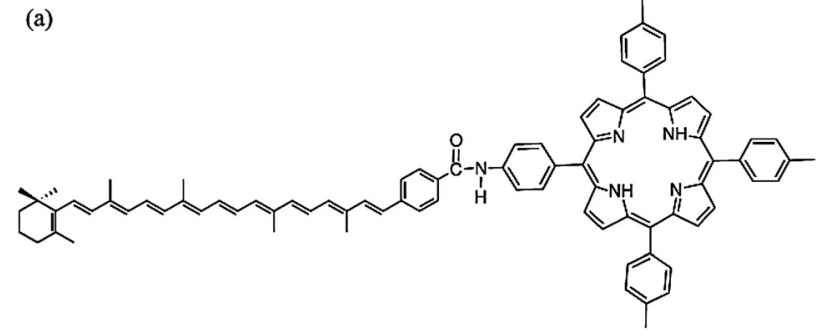

(b)

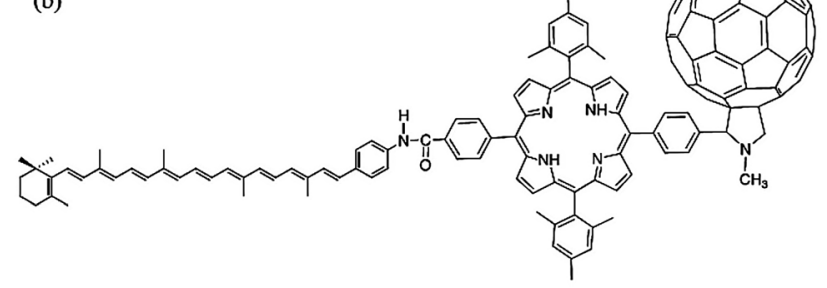

Fig. 6 (a) Carotenoid-porphyrin dyad and, (b) carotenoid-porphyrinfullerene triad with potential applications in artificial photosynthesis and photoelectrochemical devices. The figure is adapted with permission from ref. 127, Copyright (2015) Elsevier Ireland Ltd.

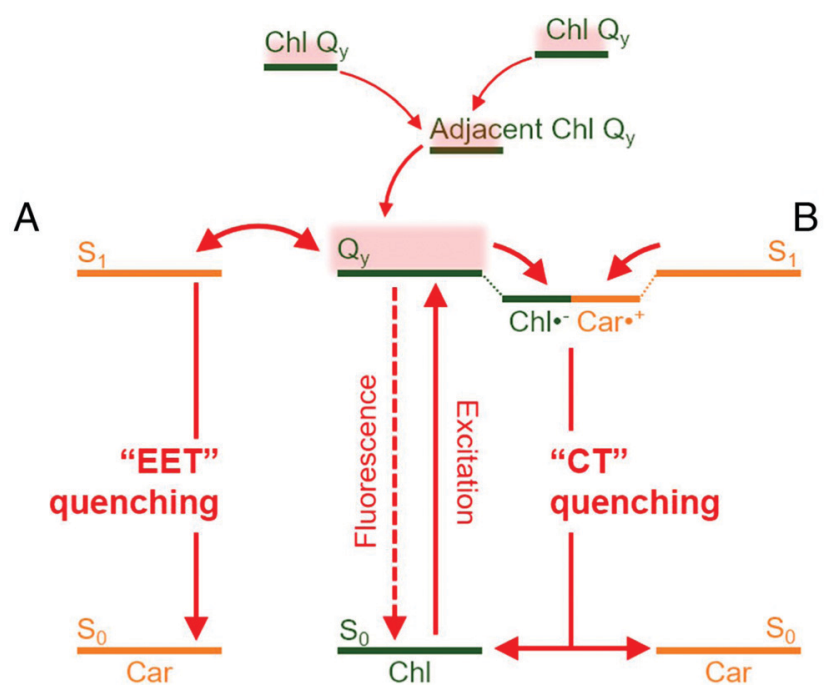

Fig. 7 Quenching mechanism in mixed chlorophyll-carotenoid (Chl-Car) systems. Chl-Car EET (A) and Chl-Car CT (B) are possible nonphotochemical quenching (NPQ) mechanisms responsible for the quenching processes. EET and $C T$ represent, excitation energy transfer and charge transfer, respectively. (CT) as possible NPQ mechanisms. The figure is adapted from ref. 133 with the permission from Proceedings of the National Academy of Sciences (PNAS).

The CT quenching is then followed by relaxation to the ground states of $\mathrm{Chl}$ and Car.

Petrella et al. presented a photochemical study using colloidal nanocrystal $\mathrm{ZnO}$ - and $\mathrm{TiO}_{2}$-modified electrodes sensitized with carotenoids and chlorophyll. ${ }^{120}$ They observed enhancement in the photosensitization and hence the photoresponse upon the nanostructured electrodes sensitization by a mixture of carotenoids and chlorophyll. The improvement was observed both in the photoelectrochemical potential and the photocurrent.
The potential increases from $\simeq 0.35 \mathrm{~V}$ (for individual carotenoid or chlorophyll sensitizers) to $\simeq 0.42 \mathrm{~V}$ for a mixture, while the current density increases from $\simeq 0.27 \mu \mathrm{A} \mathrm{cm}{ }^{-2}$ to $\simeq 1.5 \mu \mathrm{A} \mathrm{cm}^{-2}$. Moreover, as compared to the $\mathrm{TiO}_{2}$ nanocrystal electrodes, the dye-sensitized $\mathrm{ZnO}$ heterojunctions resulted in a higher photocurrent. The enhanced photoresponse of nanocrystals co-sensitized electrode could be due to the combined effect of the widening of absorption spectra and the photoprotection role of carotenoids. Antioxidant properties of carotenoids prevent the photo-oxidation damage of chlorophylls. Photoprotective nature of carotenoids has been studied by several research groups. ${ }^{29,48,134-137}$

Nagatomo et al. used $\beta$-carotene to modify photocatalytic water splitting activity of $\mathrm{KTa}(\mathrm{Zr}) \mathrm{O}_{3} \cdot{ }^{138}$ For the $\beta$-carotene based sensitizer, the formation rate of $\mathrm{H}_{2}$ increased to $360.9 \mu \mathrm{mol} \mathrm{g}$ cat $^{-1} \mathrm{~h}^{-1}$ as compared to $108 \mu \mathrm{mol} \mathrm{g}$ cat $^{-1} \mathrm{~h}^{-1}$ for without $\beta$-carotene sensitization. Despite of increased efficiency in presence of carotenoids, the reported efficiencies are too low for commercializing these systems. Further studies are required to optimize the carotenoid-based sensitization for water splitting applications. Ravi et al. ${ }^{139}$ demonstrated biohybrid photoelectrochemical transparent tandem cells by using genetically modified photosynthetic proteins, as shown in Fig. 8. They employed green and red versions of a bacterial reaction center/light harvesting protein (RC-LH1) consisting of light harvesting carotenoids. The red RC-LH1 consisted of a native red carotenoid spheroidenone (RC-LH1red). The green RC-LH1 (known as RC-LH1red) consisted of carotenoids, such as hydroxyneurosporene, neurosporene, and methoxyneurosporene. The carotenoids feed the central RC module with excited state energy. Independent RC-LH1green, RC-LH1red, and tandem RC-LH1red/ RC-LH1red, RC-LH1red/RC-LH1green and RC-LH1green/RCLH1green device architectures were investigated.

Due to complementary absorption green and red versions of RC-LH1, the green/red tandem devices demonstrate enhanced photocurrent. The results obtained by Ravi et al. are shown in Fig. 9. The individual subcells demonstrate steady-state photocurrents of $\simeq 5 \mu \mathrm{A} \mathrm{cm} \mathrm{cm}^{-2}$ and photovoltages of about $3 \mathrm{mV}$. A maximum peak current density of $\simeq 58 \mu \mathrm{A} \mathrm{cm}^{-2}$ and a steadystate photocurrent density of $\simeq 8.6 \mu \mathrm{A} \mathrm{cm}{ }^{-2}$ were observed for best performing green/red tandem cell. In the steady state, the tandem photocurrent was about $74 \%$ higher as compared to the photocurrents produced by either the green or the red subcells. Interestingly, they observed that the cells based on PEDOT:PSS outperform (12-16 fold enhancement in photocurrent) the ones based on Pt electrodes. This could be a good move towards developing cost-effective photoelectrochemical cells.

\section{Organic electronics}

\subsection{Rectification and field-effect transistors}

Nanoscale semiconductor devices with controlled rectifying function are desired in electronic device technology. Carotenoids are one of the organic molecules that offer semiconducting properties with rectifying behaviour. Burch et al. ${ }^{140}$ measured 


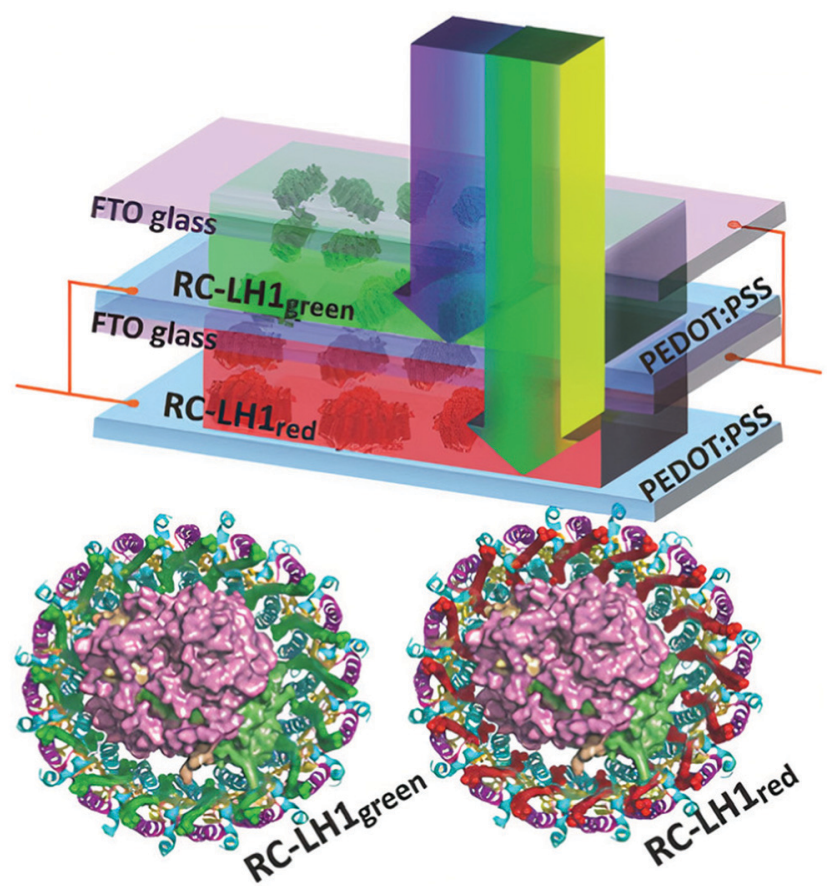

Fig. 8 A tandem device architecture consisting of red and green versions of reaction center/light harvesting complex (RC-LH1). The RC-LH1red and RCLH1green show complementary absorption in blue to yellow regions, respectively. The sub-cells were electrically connected in parallel. The light is incident from the top. The figure is adapted from ref. 139.

field-dependent mobility of five carotenoids, i.e., $\beta$-carotene, bixin, astacene, and torularhodin and isorenieratene. They observed that bixin and $\beta$-carotene show activity as fieldeffect semiconductors with p-type mobility in the range of $1 \times 10^{-7} \mathrm{~cm} \mathrm{~V}^{-2} \mathrm{~s}^{-1}$ to $1 \times 10^{-5} \mathrm{~cm} \mathrm{~V}^{-2} \mathrm{~s}^{-1}$. The $I-V$ characteristics of bixin device are shown in Fig. 10. Measured mobility values for bixin and other carotenoids are summarized in Table 4. Bixin based devices exhibited (average of 13 samples) a linear-regime field effect mobility of $3.1 \times 10^{-7} \mathrm{~cm} \mathrm{~V}^{-2} \mathrm{~s}^{-1}$, and saturated-regime field-effect mobility of $1.2 \times 10^{-7} \mathrm{~cm} \mathrm{~V}^{-2} \mathrm{~s}^{-1}$, with an average on-off ratio of 13.6. The saturated and field-effect mobility of $\beta$-carotene were found to be $1.13 \times 10^{-8} \mathrm{~cm} \mathrm{~V}^{-2} \mathrm{~s}^{-1}$ and $4.3 \times 10^{-7} \mathrm{~cm} \mathrm{~V}^{-2} \mathrm{~s}^{-1}$, respectively. Moreover they found that increased thickness of bixin and $\beta$-carotene results in reduced mobility.

Aleixo et $a .^{141}$ presented $a b$ initio quantum mechanics calculations coupled with non-equilibrium Green function to study the rectifying behaviour of a two-terminal carotenoid based device. The molecular device structures consist of molecular drain and source regions with bridge length varying between 5 and 11 double bonds. They observed that the molecular devices could be used as bi-directional symmetrical rectifier. Moreover, by integrating two devices, they proposed a single integrated device configuration to obtain field-effecttransistor (FET) and thyristor characteristics. They presented three models to explain the charge transport in the devices consisting of carotenoids molecules. Conductivity of these devices was found to decrease with the size of double bonds.
Guedes et $a .^{142}$ studied ballistic electron transport in two isomeric forms of a retinol (carotenoid) molecules, 11-cisretinol and all-trans-retinol molecules. The molecules were connected between two $\mathrm{Au}(111)$ electrodes. Using NEGF-DFT (non-equilibrium Green's function - density functional theory) calculations, they demonstrated that different isomers of carotenoids result in electron transport varying from ohmic to rectifier behavior. The 11-cis-retinol shows a symmetrical current-voltage characteristics, resulting in Ohmic like transport. On the other hand, all-trans device shows diode behaviour for a voltage range of $\sim-0.8 \mathrm{~V}$ to $+0.8 \mathrm{~V}$.

Another study by Glowacki et al. found that $\beta$-carotene can act as an electron donor with a hole mobility of $4 \times$ $10^{-4} \mathrm{~cm} \mathrm{~V}^{-2} \mathrm{~s}^{-1} \cdot{ }^{143}$ They obtained $I-V$ characteristics of $\beta$-carotene devices under dark and illuminated conditions. The $I-V$ characteristics of $\beta$-carotene devices are shown in Fig. 11. The $I-V$ characteristics show the dark rectifying nature, and illuminated $I-V$ suggesting the carotenoid to be a potential absorber in solar cells. They also found that the photocurrent increases by almost two orders when $\beta$-carotene is mixed with[6,6]-phenyl- $\mathrm{C}_{61}$-butyric acid methylester.

The rectifying and field-effect mobility characteristics of carotenoids are helpful for developing organic diodes and transistor devices. Though the mobilities of these carotenoids are not high enough to match industrial application, there are other carotenoids, both natural and synthetic which remains to be tested for increased mobilities. These are areas which have high potential for future research on sustainable organics electronics with low toxicity.

\subsection{Carotenoid nanowires}

Organic nanowires with $\pi$-conjugated double bonds are currently gaining importance in the field of molecular electronics and nanotechnology. This is due to the efficient transfer of photogenerated charge carriers to the electrodes (through $\pi$-orbital overlaps) and favouring longitudinal diffusion of excitons due to smaller grain boundaries and higher aspect ratio. ${ }^{144}$ There is also an increasing need to replace metallic wires with flexible, faster and smaller substitutes. ${ }^{145}$ Carotenoids are natural polyene conductor molecules with alternating conjugating double bond system and thus they have been considered as potential candidates in nanotechnology for molecular wires. ${ }^{146}$ Carotenoids contain highly localized $\pi$ electrons and require relatively small energy to undergo transition to comparatively low energy excited state. ${ }^{32}$ Leatherman et al. ${ }^{146}$ attached carotenoids to a gold electrode and used conducting atomic force microscopy (AFM) to measure its electrical properties (see Fig. 12). They artificially synthesized the carotenoid, (7'-apo-7'-(4-iodomethylphenyl)- $\beta$-carotene in toluene and mixed it with toluene solutions of 1-docosanethiol. The carotenoid solutions were adsorbed on the gold(111) films which were flame-annealed on mica and then analysed with the help of atomic force microscopy (AFM). They found that the carotenoid molecules in docosanethiol acted as molecular wires with resistance of $4.2-0.7 \mathrm{G} \Omega$ over a range of $1 \mathrm{~V}$ range. The conductance of these wires was over a million times greater than similar chain length saturated hydrocarbons, though not as conductive as a 
(a)

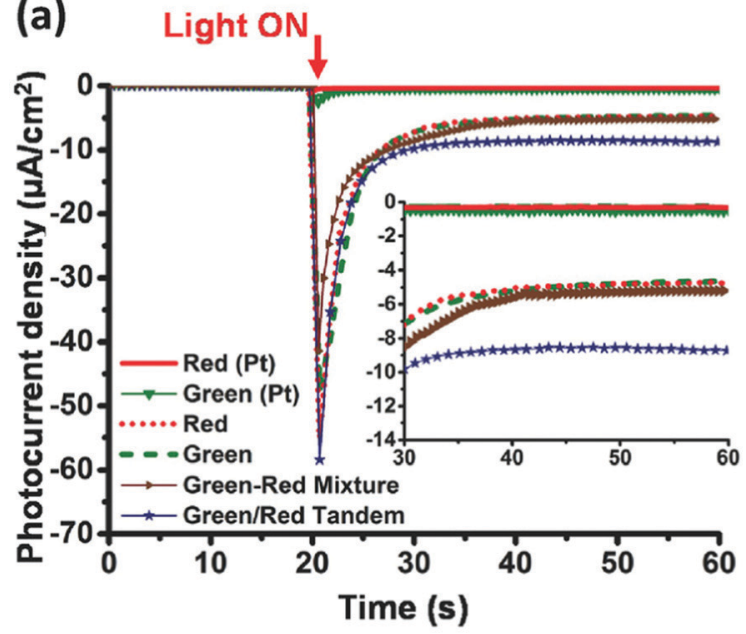

(c)

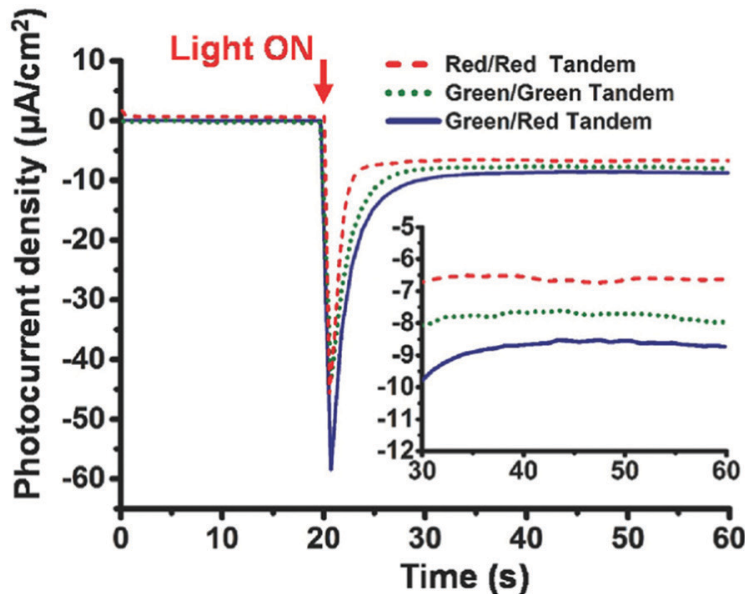

(b)

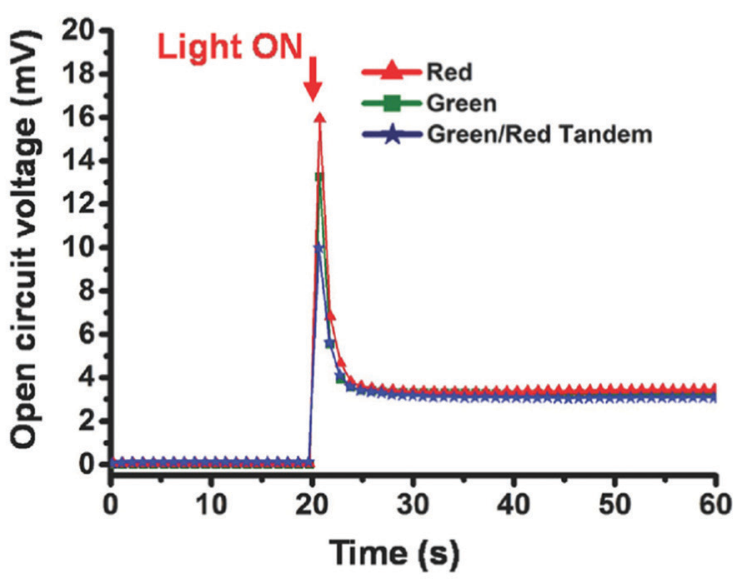

(d)

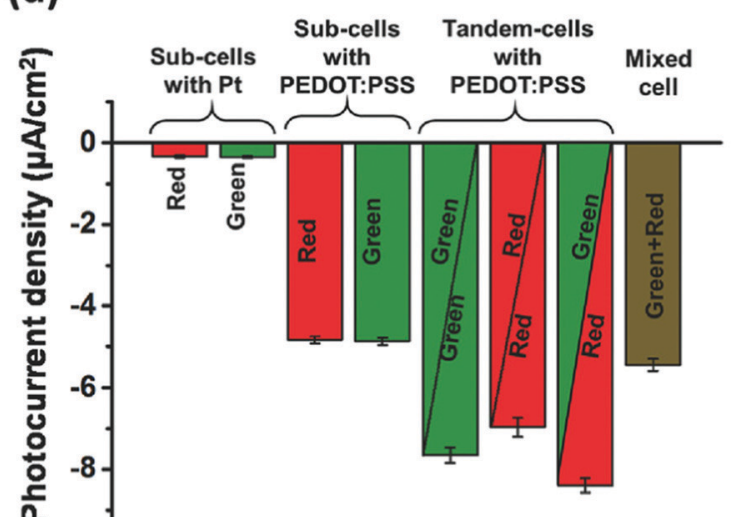

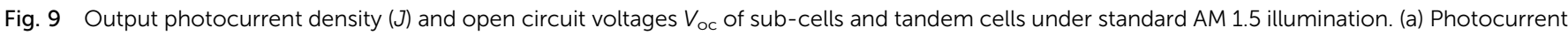

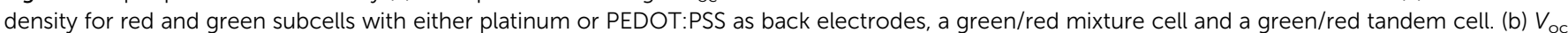

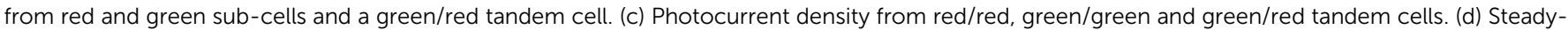

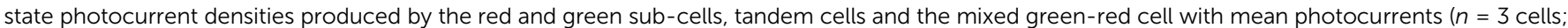
average \pm standard error). The figure is adapted from ref. 139 .

standard quantum wire. Carotenethiol is easily oxidized electrochemically, and therefore, it was hypothesized that this enhanced conductivity of carotenethiol is due to oxidation (hole transport). Their current-voltage $(I-V)$ data over $1 \mathrm{~V}$ were reproducible under anoxygenic and moisture free conditions. Furthermore, they modeled the electron-transfer by tunneling in terms of $R$ and $\lambda$ values, as described by Han et al. ${ }^{147}$ Considering a potential difference between the oxidation level and the mean Fermi energy to be $0.28 \mathrm{~V}$, Fig. 13 summarizes experimentally measured and modeled current-voltage characteristics.

Similar kind of study was conducted by Ramachandran et al. ${ }^{148}$ using 7,7'-bis(4-thiomethylphenyl)-7 and $7^{\prime}$-diapocarotene $(28 \mathrm{C})$ carotenoids. They obtained carotenoid resistance of about $5 \mathrm{G} \Omega$, similar to Leatherman et al. They also conducted theoretical modelling and found the experimentally observed molecular conductance in a good agreement (order of magnitude) with the ones predicted theoretically. Furthermore, they found that all-trans carotene is more conductive than the one with two cis-bonds by almost a factor of two. They predicted that the electron transport through this carotenoid wire is dominated via electron tunnelling, and the carotenoid conductance is much higher than an equivalent length saturated $n$-alkane.

Though the results obtained by Leatherman et al. and Ramachandran et al. were promising, the studies were limited in nature; the full nature of the conductance of carotenoid molecular wires could not be studied due to the unstable nature of carotenoids. To overcome this problem, Maeng et $a{ }^{145}$ designed a more stable carotenoid molecular wire system. They devised new carotenoid wires which they named as 2 and tried to stabilize them by joining aromatic phenyl groups at $\mathrm{C}-13$ and $\mathrm{C}^{\prime} 3^{\prime}$. These phenyl groups contained various functional elements ( $\mathrm{X}$, such as $\mathrm{Me}, \mathrm{Br}, \mathrm{H}$ and $\mathrm{OMe}$ ) at their para-positions. They also synthesized carotenoids 3 for observing the effect of each group on the conductance of carotenoid 2. Various carotenoid structures employed by Maeng et al. are summarized in Fig. 14. 


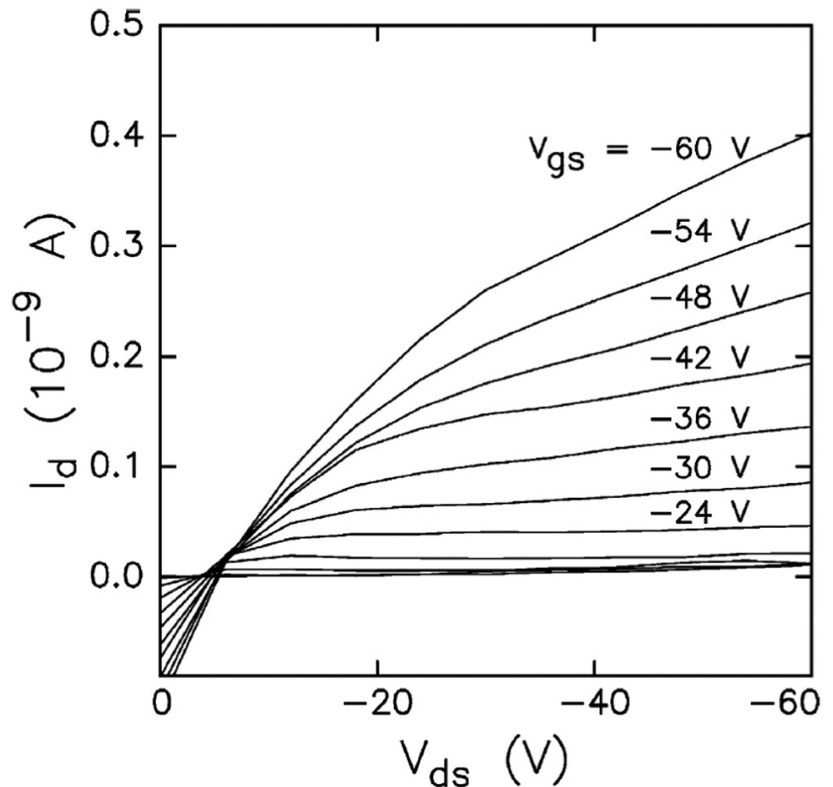

Fig. 10 Measured $I-V$ characteristics for bixin device. $V_{\mathrm{ds}}$ and $V_{\mathrm{gs}}$, represent the voltages applied between drain-source, and gate-source contacts. $I_{d}$ represents the drain current. Figure reproduced with permission from ref. 140. Copyright (2004) Elsevier B.V.

Table 4 Measured carotenoid mobilities presented by Burch et al.

\begin{tabular}{llll}
\hline Carotenoid & Thickness $(\mathrm{nm})$ & Saturated mobility & Linear mobility \\
\hline Bixin & $31.2 \pm 4.2$ & $2.75 \times 10^{-7}$ & $6.41 \times 10^{-6}$ \\
Bixin & $11.7 \pm 2.5$ & $3.10 \times 10^{-7}$ & $1.20 \times 10^{-6}$ \\
$\beta$-Carotene & $20.3 \pm 1.5$ & $1.00 \times 10^{-8}$ & $5.65 \times 10^{-6}$ \\
Astacene & $*$ & ND & ND \\
Torularhodin & $*$ & ND & ND \\
Isorenieratene & $*$ & ND & ND
\end{tabular}

Asterisk $\left({ }^{*}\right)$ mark represents the carotenoid samples deposited by using $0.5 \mathrm{wt} \%$ solutions in THF. ND represents "not dependent" on the field strength. Reprinted with permission from ref. 140. Copyright (2006) Elsevier B.V.

The carotenoids with phenyl groups were reasonably stable and they were embedded in methyl (octadecyl)sulfane (which works as an insulating support) on a gold surface. Interestingly, similar results were obtained upon measurements in both air and under inert nitrogen conditions, which was an indicator of the carotenoid stability. Also, no hysteresis was observed in the $I-V$ characteristics upon changing the voltage-scan direction. The measured $I-V$ characteristics are summarized in Fig. 15.

Carotenoid 2 showed symmetrical curves and the carotenoid 3 showed slightly asymmetrical curves. The curves also varied with the functional group attached. The highest conductance of $33.46 \mathrm{nS}$ was exhibited by carotenoid 2a containing two paraanisyl $(\mathrm{X}=\mathrm{OMe})$ groups. The para-anisyl groups are electronreleasing groups, therefore help to improve the conductance. The conductance for $\mathbf{2 a}$ was much higher (120 times) than that of shown by conventional carotenoid wires $(\mathbf{1}$, also used by Ramachandran et al.). Furthermore, it was observed that the conductance increases with the electron-donating ability of X. This increase may be due to the increase in the electron density

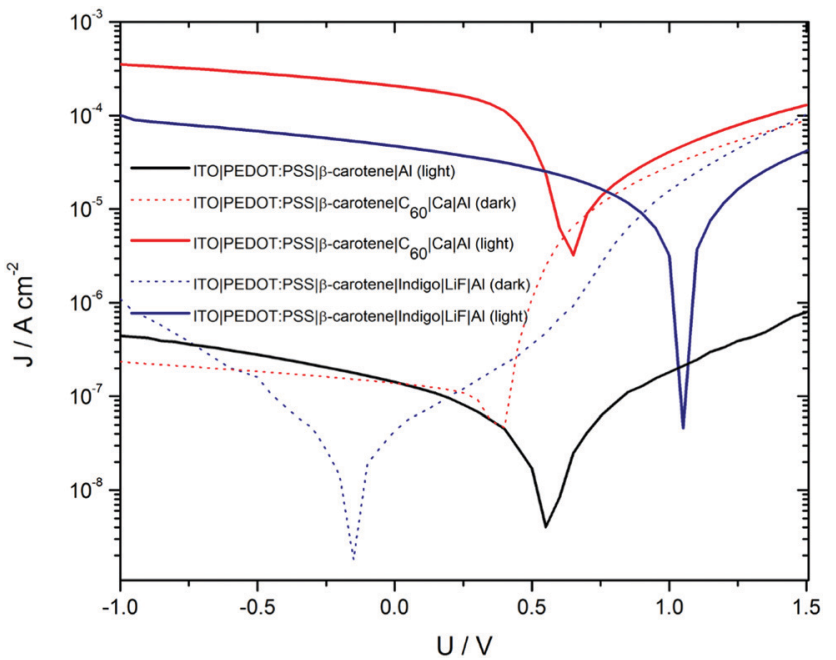

Fig. 11 Dark and illuminated $J-V$ characteristics for $\beta$-carotene device. Figure is adopted with permission from ref. 143.

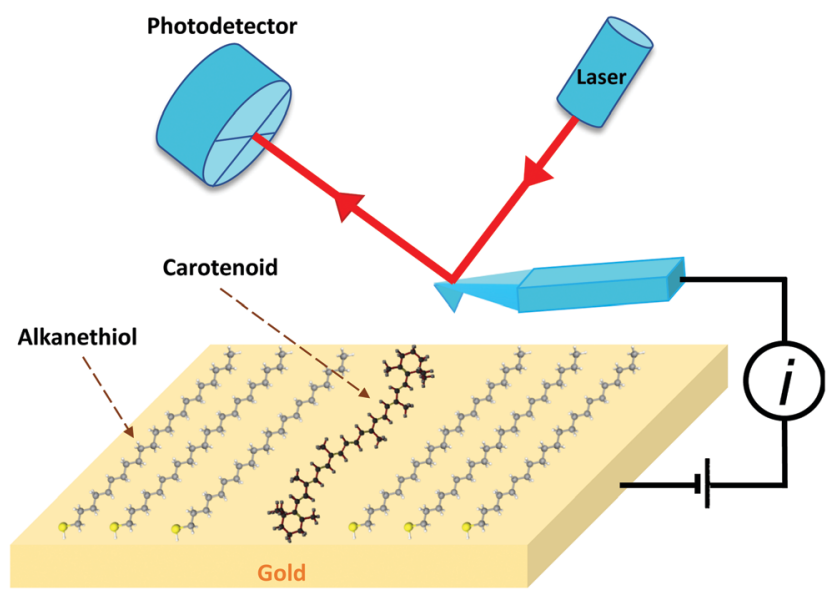

Fig. 12 Schematic representation of the experiment by Leatherman et al. ${ }^{146} \mathrm{~A}$ carotenoid is embedded in 1-docosanethiol (alkanethiol) attached to a gold surface. A voltage is applied to the gold surface, and the Pt-coated AFM cantilever is grounded. The cantilever is scanned to measure the current flow between the gold/carotenoid/cantilever system. The figure is reproduced with permission from ref. 146, copyright 1999, American Chemical Society.

of the carotenoid which places its LUMO (lowest unoccupied molecular level) near to the gold electrode Fermi Level as compared to the electron-withdrawing substituent. ${ }^{145}$

Aragones et al. ${ }^{149}$ reported that the conductivity of the carotenoid wires can be increased by twisting the phenyl groups closer to its plane. He et al. ${ }^{150}$ studied the conducting abilities of several carotenoids by synthesizing their homologues and found that the conductivity is inversely proportional to the chain length and the best molecular wires are the conjugated carotenoid chains. Also, a patent has been filed for a process to synthesize carotenoids with high electric conductivity, using $\beta$-carotene, canthaxanthene, rhodoxanthene, 3,4-dihydroanhydrorhodovibrin, spheroidene, $2,2^{\prime}$, etc. ${ }^{151}$ The potential of carotenoids as molecular wires can be further explored by 


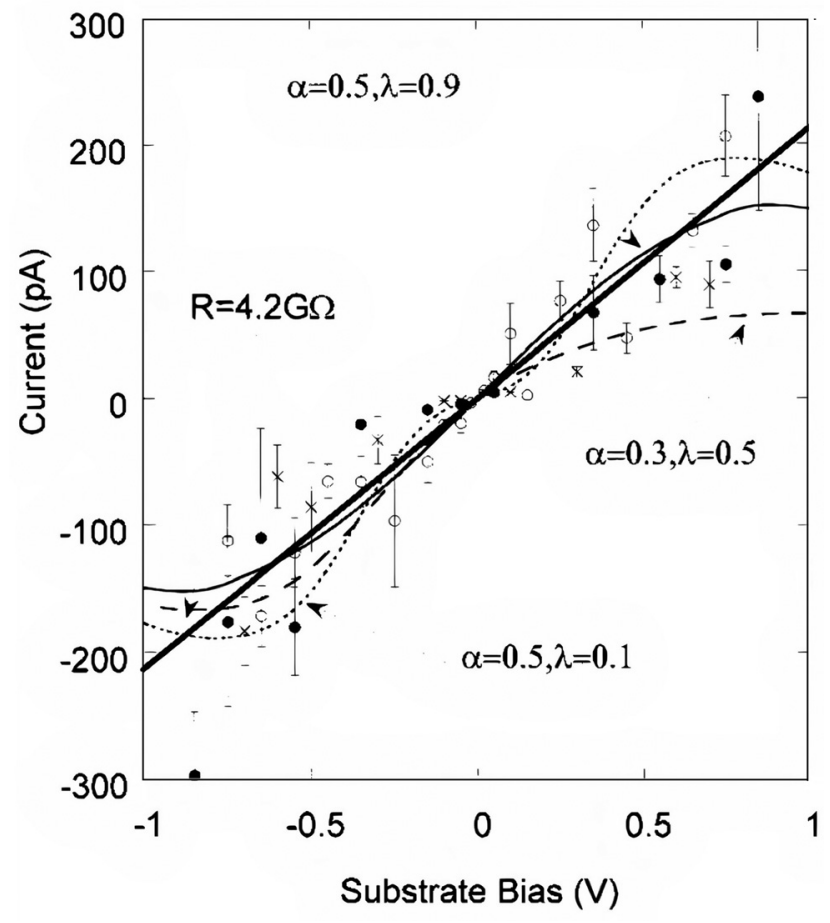

Fig. 13 Maximum current under the tip $(\mathrm{Im})$ as a function of substrate bias for three different sample preparations (open and closed circles and crosses). Contact forces are $3 \mathrm{nN}(\mathrm{O}$ and $\mathrm{X})$ and $8.5 \mathrm{nN}$ (closed circles). The error bars are (1 standard error calculated from the measured distributions. The thick solid line is a best fit to a simple ohmic model. The dashed and dotted lines are fits to a two-step electron-transfer model for different values of $R$ and $\lambda$. The figure is reproduced with permission from ref. 146. Copyright 1999, American Chemical Society.

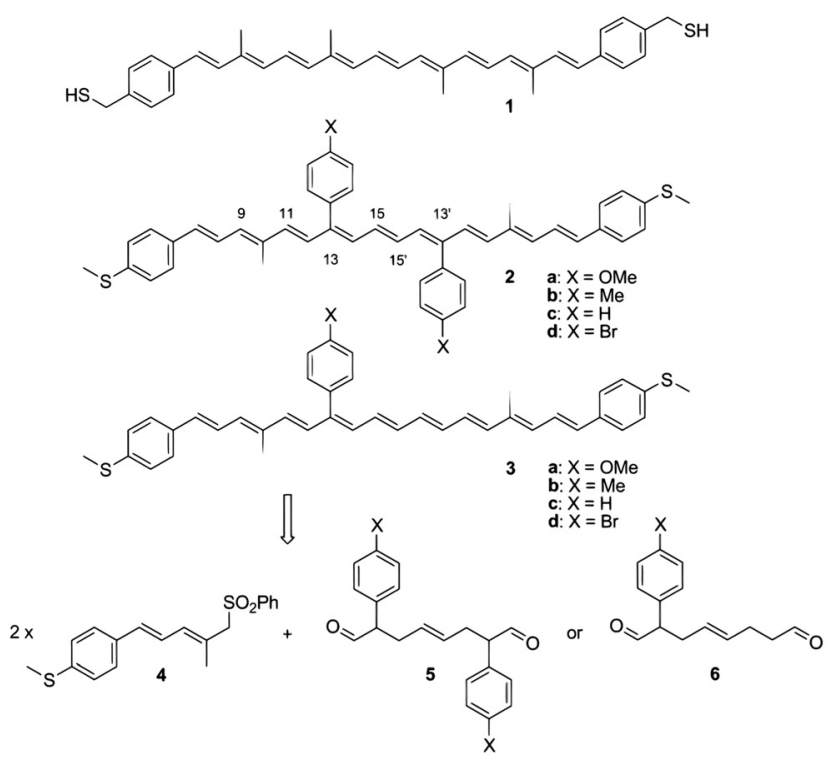

Fig. 14 Conventional carotenoid wire 1, and the novel carotenoids 2 and 3 as a single-molecular wire with conductance control, and their retro-synthetic method. Figure reproduced from ref. 145 with permission from Wiley, Copyright 2010 Wiley-VCH Verlag GmbH \& Co. KGaA, Weinheim.

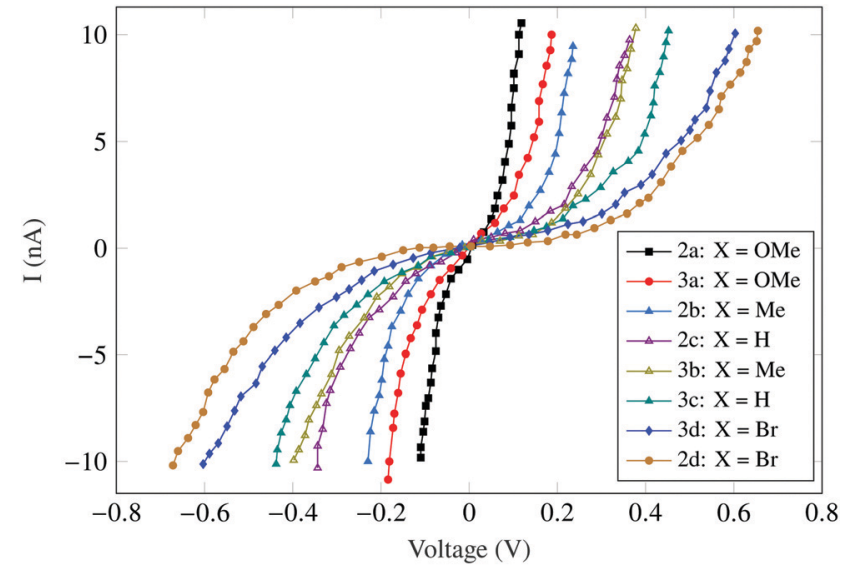

Fig. $15 \quad I-V$ curves of the novel carotenoids 2 and 3 showing different conductance values according to the electron donating or withdrawing ability of the substituent group X. Figure reproduced from ref. 145 with permission from Wiley, Copyright 2010 Wiley-VCH Verlag GmbH \& Co. KGaA, Weinheim.

using different types of carotenoids and by combining different functional groups.

Apart from molecular wires, carotenoids can also assist in synthesis of nanowires. Zhang et al. used beta-carotene to synthesize nanowires of trigonal selenium (t-Se) and nanoribbons. ${ }^{152}$ Their method was very novel, simple and eco-friendly and products formed from the oxidation of carotenoids probably acted as the template for the synthesis of the nanomaterials. This method can also be extended to other carotenoids and for the synthesis of other nanostructures.

\subsection{Light-emitting diodes}

Light-emitting diodes (LED) are electroluminescent devices that emit light when the current passes through it. LEDs are widely used in display devices, sensors, optical communication, solid-state lightening, indicators and signs, machine vision systems, biological detection, and many other applications. Currently the LED technology is dominated by inorganic materials such as GaAs, GaN, and InGaAs. These inorganic materials need controlled crystal growth and high thermal budget, making the fabrication process expensive. There have been efforts to develop LEDs based on organic-inorganic hybrid perovskite materials, but their poor stability and hazardous-lead content remain a bottleneck in their commercialization. ${ }^{153-156}$ Organic semiconductors offer solution processability, flexibility, transparency and excellent luminescent transport properties and making them a suitable choice for organic light emitting diodes (OLEDs). ${ }^{157,158}$

Unlike several organic semiconductors, much less work has been done on carotenoid based LEDs. Ohtani et al. ${ }^{137}$ fabricated OLEDs using chlorophyll and carotenoids in the active region. It was observed that the OLEDs consisting of carotenoids exhibited much longer light-emission (electroluminescent signals longer than one minute) than that without carotenoids (less than five seconds for the chlorophyll-OLEDs). Because of the antioxidant properties of carotenoids, the carotenoid rich OLEDs are resistant to the oxidation damage. 

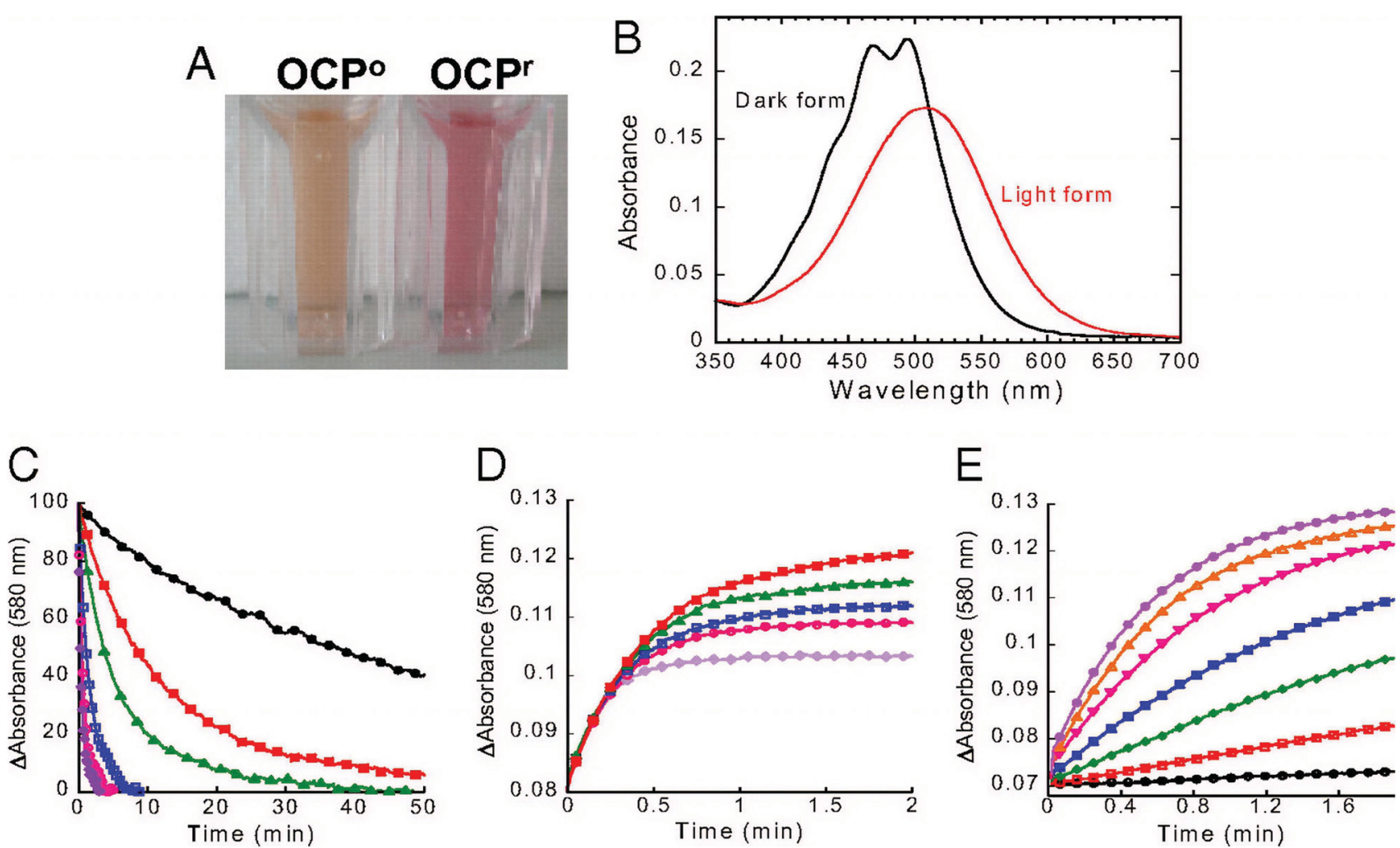

Fig. 16 Photoconversion and dark recovery presented by Wilson et al. (A) Isolated $\mathrm{OCP}^{\circ}$ and $\mathrm{OCP}^{r}$. OCP $\mathrm{OP}^{\mathrm{r}}$ was obtained by illuminating the isolated protein with a blue-green light at 740-photons for 2 at 12. (B) Absorbance spectra of the light red form (OCPr; red) and dark orange form (OCP'; black). (C) Darkness red $\mathrm{OCP}^{r}$ to orange $\mathrm{OCP}^{\circ}$ conversion (decrease of the absorbance at $580 \mathrm{~nm}$ ) and (D) OCP to OCPr conversion upon exposure of 350-photon blue-green light intensity (increase of the absorbance at $580 \mathrm{~nm}$ ) at different temperatures: 32 (violet), 28 (rose), 24 (blue), 19 (green), 15 (red), and 11 (black). (E) OCPr accumulation at 11 and different light intensities: 20 (black), 50 (red), 120 (green), 210 (blue), 350 (rose), 740 (orange), and 1200 (violet)-photons of blue-green (400-550 nm). The figure is reproduced from ref. 159, with the permission from Proceedings of the National Academy of Sciences (PNAS). Copyright (2008) National Academy of Sciences, U.S.A.

\subsection{Light sensor}

Since the photoactive protein containing carotenoids act as photoresponsive chromophores, they could be employed in light detection systems. Orange carotenoid protein (OCP) is a protein that uses a carotenoid in photoprotection in diverse cyanobacteria. ${ }^{160}$ Wilson et al. ${ }^{159}$ studied photoresponsive behavior of OCP for a potential application in light sensing. They illuminated OCP with a blue-green light source, and found that OCP transforms from dark stable orange to a red "active" form (Fig. 16). The transformation was reversible, as the red "active" form transforms back to orange form in the dark. These results point to the photoinduced structural changes in both the carotenoid and the protein. The structural changes can be quantified to measure the photosensitivity of the system to develop a light sensor.

\section{Conclusion}

Carotenoids are semiconductors with excellent photophysical, photochemical and electrochemical properties for potential application in solar harvesting. Because of their excellent photoresponse and adhesivity to $\mathrm{TiO}_{2}$, there have been several reports on using carotenoids pigments in dye-sensitized solar cells and photoelectrochemical cells. Moreover, their semiconducting nature makes them a suitable candidate for electronic devices. They are naturally available and low temperature and solution processable; therefore they can be used for cheap, lightweight, flexible, biodegradable and biocompatible electronic devices.

In solar cell devices, the carotenoids can be used not only as pure absorber, but also as redox spacer and co-sensitizers. Moreover, optimizing number and lengths of conjugated bonds, using of various carotenoid analogous, and different mesoporous scaffolds can be a way forward to obtain high efficiency naturally-inspired carotenoid-sensitized solar cells. Similarly, exploring various reaction-center complexes and $\mathrm{TiO}_{2}$ surface modifier carotenoids can help in developing high efficiency solar-water splitting system to push renewable energy applications.

With the ever-increasing use of electronic devices, electronic waste management is becoming a challenge. Most of the currently used electronic devices (such as, mobile phones, computers, CCDs, LEDs, sensors, and controllers) consist of electronic components made up of inorganic semiconductors at high temperatures. Recycling and disposal of these devices is 
not easy and environmentally friendly. Therefore, to have a sustainable development, more research is needed to develop electronic devices by using naturally-inspired and biodegradable semiconductors.

There have been proof of concept demonstration of carotenoid based rectifiers, transistors, thyristor, molecular nanowires, LEDs, and light sensors. However, among more than 700 available carotenoids, only a few of them have been studied for electronic and optoelectronic applications. New studies should focus on studying other natural and synthetic carotenoids, and to improve the existing carotenoid-based devices by incorporating or exchanging functional groups, optimizing solvent conditions and compositions of adjacent materials.

\section{Author contributions}

Both Ajay Singh and Trinetra Mukherjee contributed equally.

\section{Conflicts of interest}

The authors declare no conflict of interest.

\section{References}

1 bp, Statistical Review of World Energy 2020/69th edition, 2020, https:/www.bp.com/content/dam/bp/business-sites/ en/global/corporate/pdfs/energy-economics/statistical-review/ bp-stats-review-2020-full-report.pdf.

2 E. Stewart and P. Lemieux, IEEE International Symposium on Electronics and the Environment, 2003, pp. 271-275.

3 G. Bogdanski, M. Schönemann, S. Thiede, S. Andrew and C. Herrmann, IFIP International Conference on Advances in Production Management Systems, 2012, pp. 65-72.

4 W.-T. Tsai, H.-P. Chen and W.-Y. Hsien, J. Loss. Prev. Process Ind., 2002, 15, 65-75.

5 M. Aresta, A. Dibenedetto and A. Angelini, J. CO2 Util., 2013, 3, 65-73.

6 B. H. Robinson, Sci. Total Environ., 2009, 408, 183-191.

7 J. N. Lalena, D. A. Cleary, E. E. Carpenter and N. F. Dean, Inorganic materials synthesis and fabrication, Wiley Online Library, 2008.

$8 \mathrm{H}$. Geng and P. CMfgE, Semiconductor manufacturing handbook, McGraw-Hill Education, 2018.

9 B. El-Kareh and L. N. Hutter, Fundamentals of semiconductor processing technology, Springer Science \& Business Media, 2012.

10 T. M. Brenner, D. A. Egger, L. Kronik, G. Hodes and D. Cahen, Nat. Rev. Mater., 2016, 1, 1-16.

11 J. Berry, T. Buonassisi, D. A. Egger, G. Hodes, L. Kronik and Y.-L. O. Loo, Adv. Mater., 2015, 27, 5102-5112.

12 R. Mukherjee, Eur. J. Mol. Clin. Med., 2020, 7, 3927-3931.

13 M. Abdelkader and A. Tammam, Hybrid Perovskite Composite Materials, Elsevier, 2021, pp. 267-289.

14 W. Li, A. Stroppa, S. Gao and Z.-M. Wang, Hybrid organicinorganic perovskites, Wiley Online Library, 2020.
15 M. I. H. Ansari, A. Qurashi and M. K. Nazeeruddin, J. Photochem. Photobiol., C, 2018, 35, 1-24.

16 B.-W. Park and S. I. Seok, Adv. Mater., 2019, 31, 1805337.

17 L. Meng, J. You and Y. Yang, Nat. Commun., 2018, 9, 1-4.

18 S. R. Forrest and M. E. Thompson, Chem. Rev., 2007, 107, 923-925.

19 G. G. Malliaras, Biochim. Biophys. Acta, Gen. Subj., 2013, 1830, 4286-4287.

20 S. Ogawa, Organic Electronics Materials and Devices, Springer, 2015.

21 S. Logothetidis, Handbook of flexible organic electronics: Materials, manufacturing and applications, Elsevier, 2014.

22 A. J. Meléndez-Martnez, Mol. Nutr. Food Res., 2019, 63, 1801045.

23 G. Britton, S. Liaaen-Jensen and H. Pfander, Carotenoids: Handbook, Birkhäuser, 2012.

24 D. B. Rodriguez-Amaya, A guide to carotenoid analysis in foods, ILSI Press Washington, 2001.

25 H. Hashimoto, C. Uragami and R. J. Cogdell, Carotenoids in nature, 2016, pp. 111-139.

26 R. J. Cogdell and A. T. Gardiner, Methods Enzymol., 1993, 214, 185-193.

27 T. Maoka, J. Nat. Med., 2020, 74, 1-16.

28 H.-E. Khoo, K. N. Prasad, K.-W. Kong, Y. Jiang and A. Ismail, Molecules, 2011, 16, 1710-1738.

29 B. Demmig-Adams, Biochim. Biophys. Acta, Bioenerg., 1990, 1020, 1-24.

30 A. J. Young, Physiol. Plant., 1991, 83, 702-708.

31 G. Britton, Carotenoids, Springer, 2008, pp. 309-324.

32 G. Britton, Carotenoids, Springer, 2008, pp. 189-212.

33 T. Mukherjee, S. Bose and S. K. Mukhopadhyay, Nutrire, 2017, 42, 1-11.

34 G. Britton, S. Liaaen-Jensen and H. Pfander, Carotenoids, vol. 4: Natural functions, Springer Science \& Business Media, 2008, vol. 4.

35 H. V. Chuyen and J.-B. Eun, Crit. Rev. Food Sci. Nutr., 2017, 57, 2600-2610.

36 J. Fiedor and K. Burda, Nutrients, 2014, 6, 466-488.

37 A. Mortensen, Pure Appl. Chem., 2006, 78, 1477-1491.

38 L. Nambela, L. V. Haule and Q. Mgani, J. Clean Prod., 2020, 246, 119036.

39 A. Karmakar, A. K. Das, S. Ghosh and P. C. Sil, Carotenoids: Structure and Function in the Human Body, Springer International Publishing, 2021, pp. 189-207.

40 A. J. Meléndez-Martnez, C. M. Stinco and P. MapelliBrahm, Nutrients, 2019, 11, 1093.

41 T. P. Anunciato and P. A. da Rocha Filho, J. Cosmet. Dermatol., 2012, 11, 51-54.

42 J. Berman, U. Zorrilla-López, G. Farré, C. Zhu, G. Sandmann and R. M. Twyman, et al., Phytochem. Rev., 2015, 14, 727-743.

43 T. d. C. D. Mendes-Silva, R. F. da Silva Andrade, M. A. Ootani, P. V. D. Mendes, M. R. F. da Silva and K. S. Souza, et al., Adv. Microbiol., 2020, 10, 397-410.

$44 \mathrm{H}$. Li, S. T. Tyndale, D. D. Heath and R. J. Letcher, J. Chromatogr. B, 2005, 816, 49-56. 
45 M. J. Llansola-Portoles, A. A. Pascal and B. Robert, J. R. Soc., Interface, 2017, 14, 20170504.

46 G. Cerullo, D. Polli, G. Lanzani, S. De Silvestri, H. Hashimoto and R. J. Cogdell, Science, 2002, 298, 2395-2398.

47 H. A. Frank, A. Young, G. Britton and R. J. Cogdell, The photochemistry of carotenoids, Springer Science \& Business Media, 2006, vol. 8.

48 D. Gust, T. A. Moore and A. L. Moore, Acc. Chem. Res., 2009, 42, 1890-1898.

49 F. G. Gao, A. J. Bard and L. D. Kispert, J. Photochem. Photobiol., A, 2000, 130, 49-56.

50 J. Hammond, R. Billy and L. M. Renzi, Adv. Nutr., 2013, 4, 474-476.

51 C. Barreiro and J.-L. Barredo, Microbial Carotenoids, 2018, pp. 45-55.

52 C. S. Boon, D. J. McClements, J. Weiss and E. A. Decker, Crit. Rev. Food Sci. Nutr., 2010, 50, 515-532.

53 N. Mariotti, M. Bonomo, L. Fagiolari, N. Barbero, C. Gerbaldi and F. Bella, et al., Green Chem., 2020, 22, 7168-7218.

54 J. Moser and M. Graetzel, J. Am. Chem. Soc., 1984, 106, 6557-6564.

55 R. Rossetti and L. E. Brus, J. Am. Chem. Soc., 1984, 106, 4336-4340.

56 A. Hagfeldt, G. Boschloo, L. Sun, L. Kloo and H. Pettersson, Chem. Rev., 2010, 110, 6595-6663.

57 E. Yamazaki, M. Murayama, N. Nishikawa, N. Hashimoto, M. Shoyama and O. Kurita, Sol. Energy, 2007, 81, 512-516.

58 T. Ruiz-Anchondo, N. Flores-Holgun and D. GlossmanMitnik, Molecules, 2010, 15, 4490-4510.

59 S. Kishimoto, T. Maoka, K. Sumitomo and A. Ohmiya, Biosci., Biotechnol., Biochem., 2005, 69, 2122-2128.

60 M. A. Al-Alwani, A. B. Mohamad, N. A. Ludin, A. A. H. Kadhum and K. Sopian, Renewable Sustainable Energy Rev., 2016, 65, 183-213.

61 Y. Peng, C. Ma, Y. Li, K. S.-Y. Leung, Z.-H. Jiang and Z. Zhao, Plant Foods Hum. Nutr., 2005, 60, 161-164.

62 N. Mohd Hassan, N. A. Yusof, A. F. Yahaya, N. N. Mohd Rozali and R. Othman, Antioxidants, 2019, 8, 469.

63 W. L. Hadden, R. H. Watkins, L. W. Levy, E. Regalado, D. M. Rivadeneira and R. B. van Breemen, et al., J. Agric. Food Chem., 1999, 47, 4189-4194.

64 Y.-C. Wang, Y.-C. Chuang and H.-W. Hsu, Food Chem., 2008, 106, 277-284.

65 K. Hemalatha, S. Karthick, C. J. Raj, N.-Y. Hong, S.-K. Kim and H.-J. Kim, Spectrochim. Acta, Part A, 2012, 96, 305-309.

66 N. Órdenes-Aenishanslins, G. Anziani-Ostuni, M. VargasReyes, J. Alarcón, A. Tello and J. Pérez-Donoso, J. Photochem. Photobiol., B, 2016, 162, 707-714.

67 T. Montagni, P. Enciso, J. J. Marizcurrena, S. CastroSowinski, C. Fontana and D. Davyt, et al., Environ. Sustain., 2018, 1, 89-97.

68 S. K. Srivastava, P. Piwek, S. R. Ayakar, A. Bonakdarpour, D. P. Wilkinson and V. G. Yadav, Small, 2018, 14, 1800729.

69 N. Gómez-Ortz, I. Vázquez-Maldonado, A. Pérez-Espadas, G. Mena-Rejón, J. Azamar-Barrios and G. Oskam, Sol. Energy Mater. Sol. Cells, 2010, 94, 40-44.
70 C. P. Eka, B. Yuliarto and S. Suyatman, Adv. Mater. Res., 2013, 167-170.

71 V. Shanmugam, S. Manoharan, S. Anandan and R. Murugan, Spectrochim. Acta, Part A, 2013, 104, 35-40.

72 M. Khalili, M. Abedi and H. S. Amoli, Ionics, 2017, 23, 779-787.

73 H. Zhou, L. Wu, Y. Gao and T. Ma, J. Photochem. Photobiol., A, 2011, 219, 188-194.

74 A. Curl and G. Bailey, J. Agric. Food Chem., 1957, 5, 605-608.

75 S. Hao, J. Wu, Y. Huang and J. Lin, Sol. Energy, 2006, 80, 209-214.

76 D. Alwis, U. Chandrika and P. Jayaweera, J. Photochem. Photobiol., A, 2021, 407, 113061.

77 G. Calogero, J. Barichello, I. Citro, P. Mariani, L. Vesce and A. Bartolotta, et al., Dyes Pigm., 2018, 155, 75-83.

78 L. A. DeSilva, P. Pitigala, A. Gaquere-Parker, R. Landry, J. Hasbun and V. Martin, et al., J. Mater. Sci.: Mater. Electron., 2017, 28, 7724-7729.

79 X.-F. Wang, Y. Koyama, H. Nagae, Y. Yamano, M. Ito and Y. Wada, Chem. Phys. Lett., 2006, 420, 309-315.

80 T. M. El-Agez, A. A. El Tayyan, A. Al-Kahlout, S. A. Taya and M. S. Abdel-Latif, Int. J. Mater. Chem., 2012, 2, 105-110.

81 K. Moustafa, M. Rekaby, E. El Shenawy and N. Khattab, J. Appl. Sci. Res., 2012, 8, 4393-4404.

82 R. Suryana and A. Supriyanto, Mater. Sci. Forum, 2013, 15-19.

83 K. H. Park, T. Y. Kim, J. Y. Park, E. M. Jin, S.-H. Yim and J. G. Fisher, et al., J. Electroanal. Chem., 2013, 689, 21-25.

84 K. Wongcharee, V. Meeyoo and S. Chavadej, Sol. Energy Mater. Sol. Cells, 2007, 91, 566-571.

85 M. Narayan and A. Raturi, Appl. Sol. Energy, 2011, 47, 112-117.

86 I. C. Maurya, P. Srivastava and L. Bahadur, Opt. Mater., 2016, 52, 150-156.

87 N. Li, N. Pan, X. Li and S. Lin, Mater. Res. Innov., 2014, 18, S4-S18.

88 A. Lim, N. Haji Manaf, K. Tennakoon, R. Chandrakanthi, L. B. L. Lim and J. Bandara, et al., J. Biophys., 2015, 510467.

89 X.-F. Wang, Y. Koyama, Y. Wada, S.-I. Sasaki and H. Tamiaki, Chem. Phys. Lett., 2007, 439, 115-120.

90 N. Li, N. Pan, D. Li and S. Lin, Int. J. Photoenergy, 2013, 598753.

91 A. Singh, E. Radicchi, S. Fantacci, F. Nunzi, F. De Angelis and A. Gagliardi, J. Phys. Chem. C, 2019, 123, 14955-14963.

92 S. Rühle, M. Greenshtein, S.-G. Chen, A. Merson, H. Pizem, C. S. Sukenik, D. Cahen and A. Zaban, J. Phys. Chem. B, 2005, 109, 18907-18913.

93 X.-F. Wang, L. Wang, Z. Wang, Y. Wang, N. Tamai, Z. Hong and J. Kido, J. Phys. Chem. C, 2013, 117, 804-811.

94 T. Zhuang, S.-i. Sasaki, T. Ikeuchi, J. Kido and X.-F. Wang, RSC Adv., 2015, 5, 45755-45759.

95 A. Petrella, P. Cozzoli, M. Curri, M. Striccoli, P. Cosma and A. Agostiano, Bioelectrochemistry, 2004, 63, 99-102.

96 X.-F. Wang, J. Xiang, P. Wang, Y. Koyama, S. Yanagida and Y. Wada, et al., Chem. Phys. Lett., 2005, 408, 409-414.

97 X.-F. Wang, A. Matsuda, Y. Koyama, H. Nagae, S.-I. Sasaki, H. Tamiaki and Y. Wada, Chem. Phys. Lett., 2006, 423, 470-475. 
98 X.-F. Wang, R. Fujii, S. Ito, Y. Koyama, Y. Yamano, M. Ito, T. Kitamura and S. Yanagida, Chem. Phys. Lett., 2005, 416, 1-6.

99 F. Kabir, S. N. Sakib and N. Matin, Optik, 2019, 181, 458-464. 100 R. Harikisun and H. Desilvestro, Sol. Energy, 2011, 85, 1179-1188.

101 B. Tian and Y. Hua, Trends Microbiol., 2010, 18, 512-520.

102 M. R. Hoffmann, S. T. Martin, W. Choi and D. W. Bahnemann, Chem. Rev., 1995, 95, 69-96.

103 L. X. Chen, T. Rajh, Z. Wang and M. C. Thurnauer, J. Phys. Chem. B, 1997, 101, 10688-10697.

104 K. Nakata and A. Fujishima, J. Photochem. Photobiol., C, 2012, 13, 169-189.

105 X. Chen and A. Selloni, Chem. Rev., 2014, 114, 9281-9282. 106 Y. Cai and Y. P. Feng, Prog. Surf. Sci., 2016, 91, 183-202.

107 T. A. Konovalova, L. D. Kispert and V. V. Konovalov, J. Phys. Chem. B, 1999, 103, 4672-4677.

108 A. J. Haider, Z. N. Jameel and I. H. Al-Hussaini, Energy Procedia, 2019, 157, 17-29.

109 R. Daghrir, P. Drogui and D. Robert, Ind. Eng. Chem. Res., 2013, 52, 3581-3599.

110 H. Park, Y. Park, W. Kim and W. Choi, J. Photochem. Photobiol., C, 2013, 15, 1-20.

111 T. A. Heimer and E. J. Heilweil, J. Phys. Chem. B, 1997, 101, 10990-10993.

112 M. C. Thurnauer, T. Rajh and M. Tiede, Acta Chem. Scand., 1997, 51, 610-618.

113 O. I. Micic, Y. Zhang, K. R. Cromack, A. D. Trifunac and M. C. Thurnauer, J. Phys. Chem., 1993, 97, 7277-7283.

114 J. Pan, Y. Xu, L. Sun, V. Sundström and T. Polvka, J. Am. Chem. Soc., 2004, 126, 3066-3067.

115 J. Turner, T. Deutsch, J. Head and P. Vallett, Photoelectrochemical water systems for $\mathrm{H} 2$ production, DOE Hydrogen Program Annual Merit Review, 2007.

116 Y.-H. Chiu, T.-H. Lai, M.-Y. Kuo, P.-Y. Hsieh and Y.-J. Hsu, APL Mater., 2019, 7, 080901.

117 S. K. Ngoh and D. Njomo, Renewable Sustainable Energy Rev., 2012, 16, 6782-6792.

118 C. X. Kronawitter, L. Vayssieres, S. Shen, L. Guo, D. A. Wheeler and J. Z. Zhang, et al., Energy Environ. Sci., 2011, 4, 3889-3899.

119 A. Fujishima and K. Honda, Nature, 1972, 238, 37-38.

120 A. Petrella, P. Cosma, M. L. Curri, S. Rochira and A. Agostiano, J. Nanoparticle Res., 2011, 13, 6467-6481.

121 N. E. Polyakov, T. V. Leshina, E. S. Meteleva, A. V. Dushkin, T. A. Konovalova and L. D. Kispert, J. Phys. Chem. B, 2010, 114, 14200-14204.

122 D. Gust, T. A. Moore and A. L. Moore, Acc. Chem. Res., 1993, 26, 198-205.

123 T. A. Moore, D. Gust, P. Mathis, J.-C. Mialocq, C. Chachaty and R. V. Bensasson, et al., Nature, 1984, 307, 630-632.

124 R. Berera, C. Herrero, I. H. Van Stokkum, M. Vengris, G. Kodis and R. E. Palacios, et al., Proc. Natl. Acad. Sci. U. S. A., 2006, 103, 5343-5348.

125 F. Fungo, L. Otero, E. Durantini, W. J. Thompson, J. J. Silber and T. A. Moore, et al., Phys. Chem. Chem. Phys., 2003, 5, 469-475.
126 Y. Liu, Y. Li, G. Chen, X.-F. Wang, R. Fujii and Y. Yamano, et al., Adv. Mater. Interfaces, 2021, 8, 2101303.

127 H. Hashimoto, Y. Sugai, C. Uragami, A. T. Gardiner and R. J. Cogdell, J. Photochem. Photobiol., C, 2015, 25, 46-70.

128 G. Kodis, P. A. Liddell, A. L. Moore, T. A. Moore and D. Gust, J. Phys. Org. Chem., 2004, 17, 724-734.

129 Y. Tachibana, L. Vayssieres and J. R. Durrant, Nat. Photonics, 2012, 6, 511.

130 W. Wang, J. Chen, C. Li and W. Tian, Nat. Commun., 2014, 5, 1-8.

131 W. Lubitz, E. J. Reijerse and J. Messinger, Energy Environ. Sci., 2008, 1, 15-31.

132 A. J. Wilson and P. K. Jain, J. Am. Chem. Soc., 2018, 140, 5853-5859.

133 S. Park, C. J. Steen, D. Lyska, A. L. Fischer, B. Endelman and M. Iwai, et al., Proc. Natl. Acad. Sci. U. S. A., 2019, 116, 3385-3390.

134 Y. B. Slonimskiy, E. G. Maksimov, E. P. Lukashev, M. Moldenhauer, T. Friedrich and N. N. Sluchanko, Biochim. Biophys. Acta, Bioenerg., 2020, 1861, 148174.

135 H. Bao, M. R. Melnicki and C. A. Kerfeld, Curr. Opin. Plant Biol., 2017, 37, 1-9.

136 R. L. Leverenz, D. Jallet, M.-D. Li, R. A. Mathies, D. Kirilovsky and C. A. Kerfeld, Plant Cell, 2014, 26, 426-437.

137 N. Ohtani, N. Kitagawa and T. Matsuda, Jpn. J. Appl. Phys., 2011, 50, 01BC08.

138 M. Nagatomo, H. Hagiwara, S. Ida and T. Ishihara, Electrochemistry, 2011, 79, 779-782.

139 S. K. Ravi, Z. Yu, D. J. Swainsbury, J. Ouyang, M. R. Jones and S. C. Tan, Adv. Energy Mater., 2017, 7, 1601821.

140 R. R. Burch, Y.-H. Dong, C. Fincher, M. Goldfinger and P. E. Rouviere, Synth. Met., 2004, 146, 43-46.

141 V. F. Aleixo, A. C. Saraiva and J. Del Nero, Int. J. Nucl. Quantum Eng., 2012, 6, 757-760.

142 A. Guedes, S. Corrêa, D. Ferreira, M. Siqueira, R. Gester, A. Neto and J. Del Nero, J. Mol. Model., 2018, 24, 1-9.

143 E. D. Glowacki, L. Leonat, G. Voss, M. Bodea, Z. Bozkurt, M. Irimia-Vladu, et al., Organic Semiconductors in Sensors and Bioelectronics IV, 2011, p. 81180M.

144 A. Jain and S. J. George, Nat. Nanotechnol., 2016, 11, 843-844.

145 J. Maeng, S. B. Kim, N. J. Lee, E. Choi, S.-Y. Jung and I. Hong, et al., Chem. - Eur. J., 2010, 16, 7395-7399.

146 G. Leatherman, E. Durantini, D. Gust, T. A. Moore, A. L. Moore and S. Stone, et al., J. Phys. Chem. B, 1999, 103, 4006-4010.

147 W. Han, E. N. Durantini, T. A. Moore, A. L. Moore, D. Gust and P. Rez, et al., J. Phys. Chem. B, 1997, 101, 10719-10725.

148 G. K. Ramachandran, J. K. Tomfohr, J. Li, O. F. Sankey, X. Zarate and A. Primak, et al., J. Phys. Chem. B, 2003, 107, 6162-6169.

149 A. C. Aragonès, N. Darwish, J. Im, B. Lim, J. Choi and S. Koo, et al., Chem. - Eur. J., 2015, 21, 7716-7720.

150 J. He, F. Chen, J. Li, O. F. Sankey, Y. Terazono and C. Herrero, et al., J. Am. Chem. Soc., 2005, 127, 1384-1385. 
151 F. Feichtmayr, H. Naarmann, J. Paust and K. Penzien, Preparation of electrically conductive carotenoids, US Pat., 4336201, 1982.

152 B. Zhang, X. Ye, W. Dai, W. Hou, F. Zuo and Y. Xie, Nanotechnology, 2005, 17, 385.

153 C. Zhao, D. Zhang and C. Qin, CCS Chem., 2020, 2, 859-869.

154 Q. Dong, L. Lei, J. Mendes and F. So, J. Phys. Mater., 2020, 3, 012002.

155 C. Zou, C. Zhang, Y.-H. Kim, L. Y. Lin and J. M. Luther, ACS Photonics, 2021, 8, 386-404.
156 A. Tiwari, N. S. Satpute, C. M. Mehare and S. Dhoble, J. Alloys Compd., 2020, 156827.

157 S.-J. Zou, Y. Shen, F.-M. Xie, J.-D. Chen, Y.-Q. Li and J.-X. Tang, Mater. Chem. Front., 2020, 4, 788-820.

158 S. Tiwari, M. Singh, S. Mishra and A. Shrivastava, J. Nanoelectron. Optoelectron., 2019, 14, 1215-1224.

159 A. Wilson, C. Punginelli, A. Gall, C. Bonetti, M. Alexandre and J.-M. Routaboul, et al., Proc. Natl. Acad. Sci. U. S. A., 2008, 105, 12075-12080.

160 D. Kirilovsky and C. A. Kerfeld, Photochem. Photobiol. Sci., 2013, 12, 1135-1143. 